\title{
Criminal Liability in ADHD Subjects under the Spanish Criminal Law*
}

\author{
Marta M. Aguilar Cárceles, David L. Morillas Fernández \\ Department of Legal History and Criminal Sciences and Criminology, Faculty of Law, University of \\ Murcia, Murcia, Spain \\ Email:maguilarcarceles@um.es,davidm@um.es
}

Received 28 September 2015; accepted 27 November 2015; published 30 November 2015

Copyright (C) 2015 by authors and Scientific Research Publishing Inc.

This work is licensed under the Creative Commons Attribution International License (CC BY). http://creativecommons.org/licenses/by/4.0/

(c) (i) Open Access

\section{Abstract}

The aim of the present article is to focus on the general hypothesis of the possible link between the Attention-Deficit Hyperactivity Disorder (ADHD) individual diagnosis and the risk to develop disruptive and antisocial behaviors that may lead to the commission of unlawful acts in the future. Mainly when there is a severe disorder that can affect the comprehension of the criminal liability in the defendant. This idea is based on several studies and researches that in recent years have raised the question about ADHD and criminal behavior. The search for an answer to the question above is justified by the confluence of various fields of knowledge, which confirms that the analysis carried out has been established on the multidisciplinary and interdisciplinary study of ADHD. Specifically, the research has focused its target to Sciences such are Psychology, Criminology and Criminal Law. That is why we are going to divide the analysis in different section, starting with the general ones (concept, diagnostic criteria, comorbidity, the new structure of DSM and its influence on ADHD) to continue with the most specific aspects (criminal behavior, criminal liability). Finally, the last part of the article is dedicated to know which is the legal opinion and treatment by the Spanish Criminal Law.

\section{Keywords}

Attention-Deficit Hyperactivity Disorder (ADHD), Diagnostic Criteria, Comorbidity, Antisocial Behavior, Criminal Liability

\footnotetext{
"This article is made following an interdisciplinary point of view. ADHD is one of the most diagnosed mental pathologies all over the world and find out an answer to this problem requires a wide overview of the disorder. In this sense, we analyze the disorder form different scientific perspectives (Psychology, Criminology and Criminal Law). Marta M. Aguilar Cárceles is Forensic Psychologist, Criminologist and has the Degree in Law. She currently works as an Associate Professor. David L. Morillas Fernández actually works as a Permanent Lecturer. Both of them teach Criminal Law, Criminology and Victimology and belong to the Department of Legal History and Criminal Sciences and Criminology in the Faculty of Law of the University of Murcia (Spain).
} 


\section{Introduction}

The Attention-Deficit and Hyperactivity Disorder (ADHD) is considered as the most predominant mental psychopathology in childhood worldwide whose main symptoms are defining in lack of attention, hyperactivity and impulsiveness (Fletcher \& Wolfe, 2009; Froehlich, McCough, \& Stein, 2010; San Sebastián Cabases, Soutullo Esperón, \& Figueroa Quintana, 2010) ${ }^{1}$. The possibility of its appearance during adolescence and adulthood influenced by a group of clinically significant factors and other wide variety of risk factors would define the Disorder as a chronic psychopathology with severe consequences which can lead the individual to the development of an antisocial and illicit behavior and its implication in the Criminal Legal System (Rachel, Klein, \& Manuzza, 1991; Castejón, 2011).

This Disorder is diagnosed in the first years of life after the discernment of symptoms of lack of attention, hyperactivity and impulsiveness. Its main characteristics are a disturbance of the performing function at encephalon level which would include, among other consequences, the inability to deal with certain stimulus, planning, thinking about the consequences of future actions or refraining the conduct facing certain stimulus when the self-regulation is possible by more suitable responses. In this sense, Barkley (2006: p. 81) affirms that self-regulation may be the key that makes possible to distinguish ADHD from other disorders.

Due to the particular symptomatology of the disorder and the medical meaning that its consequences can have in the short and long-term, which can become socially reprehensible and even illicit conducts, we could say that the original hypothesis arises from the necessity of laying out until what extent a connection of the disorder would exist so that it would be possible to explain the achievement of these results by itself.

Attending to all above, we deal with the multidisciplinary and interdisciplinary analysis of the disorder under the aforementioned Sciences justifying its main hypothesis in determining the possible link of the Disorder with a following criminal path. We will mainly focus on Psychology, Criminology and Criminal Law (Figure 1) ${ }^{2}$.

Following the previous information and leading to a bigger analysis of the Attention-Deficit and Hyperactivity Disorder regarding the aspects that could explain the mentioned relation, the structure of the article is established over a thorough analysis of the different aspects which could define the Disorder, that is, from its conception and delimiting characteristics until its biological components, psychological limits and determining social factors which be risk for a following antisocial and criminal path. More specifically, setting the limits of the work by sections, it is divided in a general part and in a more specific one in which we will try to answer about the requiring consequences to the individuals that, being affected by the Attention-Deficit and Hyperactivity Disorder, take action against the Law. We start appreciating how the most generic and introductory parts about the Disorder give way to the specific aims. Starting with the preliminary questions about the conceptual definition of ADHD and its reflection in major international manuals like ICD and DSM (current characterization of the Disorder, its etiological aspects, course and outcome, clinical description according to diagnostic criteria as are inattention, hyperactivity and impulsivity) and following with the establishment of them on the various stages of development. After that, the Work continues explaining the relevance of biological determinants of the Pathology, highlighting the genetic, neuroanatomical and chemical aspects, and the possible existence of comorbid symptoms or disorders. From this point on, it will be ready to analyze the risk of developing antisocial and illegal behaviors later which, ultimately, will lead to consideration of the unlawful conduct and enforceability, or

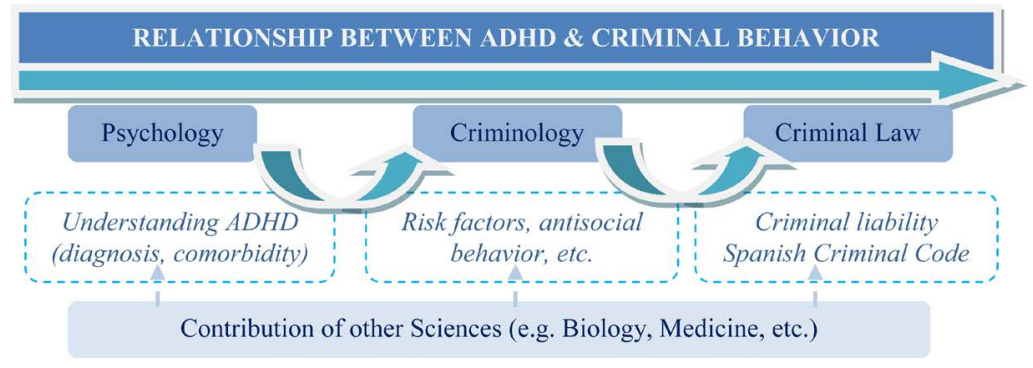

Figure 1. Comprehension of ADHD from different sciences.

${ }^{1}$ Further information in Academy of Pediatrics (2000). Clinical practice guidelines: diagnosis and evaluation of the child with attentiondeficit/hyperactivity disorder. Pediatrics, 105, 1158-1170. http://pediatrics.aappublications.org/content/105/5/1158

${ }^{2}$ It does not mean that we do not consider the contribution of other Sciences such are Biology or Medicine, we only want to expose the most direct connection between Psychology, Criminology and Criminal Law according to our purpose (ADHD and criminality). 
not, of criminal responsibility.

Specifically, to make this analysis easier, this article is divided into seven sections. The introduction sketches the main issue, and the significance of this study. The articulated definition of ADHD and its main characteristics are presented in the Section 2, joined to the evolution of the terminology of the concept in its new location by the APA, 2) the symptomatology and stability of the disorder in the different stages of development, including diagnosis criteria and the question about the persistence between symptoms and Disorder. On the other hand, the neurobiological and genetic explanations by the medical investigations at international level, etiophatology due to social factors, and main models in the explanation of ADHD functions are submitted in Section 3. In Section 4, we are going to remarks some points related to the comorbidity with other pathologies and in Section 5 we focus on the origin of the Disorder clarified by several risk social factors-all of this supported by the best Criminology Theories, joined to the explanation of crimes and other important aspects of prison population with Attention-Deficit and Hyperactivity Disorder related to the two field research carried out in this population-. In Section 6, examination is given to the explanation of the relationship between the ADHD and the Criminal Justice System, when the worst consequences of ADHD come from its persistence, where we are going to assess criminal liability and charges. Finally, in Section 7, this article finishes by the conclusions.

This template, created in MS Word 2007, provides authors with most of the formatting specifications needed for preparing electronic versions of their papers. All standard paper components have been specified for three reasons: 1) ease of use when formatting individual papers; 2) automatic compliance to electronic requirements that facilitate the concurrent or later production of electronic products; and 3) conformity of style throughout a journal paper. Margins, column widths, line spacing, and type styles are built-in; examples of the type styles are provided throughout this document and are identified in italic type, within parentheses, following the example. Some components, such as multi-leveled equations, graphics, and tables are not prescribed, although the various table text styles are provided. The formatter will need to create these components, incorporating the applicable criteria that follow.

\section{Global Considerations about the Attention-Deficit Hyperactivity Disorder (ADHD)}

\subsection{Current Definition inside the Neurodevelopmental Disorders and Diagnostic Criteria Comparison}

The first cases start in the middle of the $19^{\text {th }}$ century but it is one century later when its configuration is established internationally when it appears in the DSM-III in the year 1980 (Figure 2 encompassed and reviewed its denominations over the years) ${ }^{3}$. More concrete, it appears in the Chapter related to the disorders in the early childhood and adolescence, which is placed with the behavioral disorders. Specifically, the publication of the 3rd Edition of the American Psychiatric Association (APA) is the moment in which the scientific birth of the Disorder is recognized-changing its systematization and location since 2013.

Since 2013, the reorganization of psychopathologies described in the Diagnostic and Statistical Manual of Mental Disorders (DSM) take the Attention-Deficit and Hyperactivity Disorder (named this way specifically by the American Psychiatric Association or APA $)^{4}$ to the group of neurodevelopmental disorders on the margins of the disruptive disorders, impulse control, and conduct disorders, where the mentioned behavioral disorder is placed. In spite of that, the APA affirms that the research data would also support its possible inclusion with these disorders.

The recent inclusion of the Attention-Deficit and Hyperactivity Disorder in the Neurodevelopmental Disorders shows important connotations in the assessment of the illness, mainly due to the separation that, at first sight,

\footnotetext{
${ }^{3}$ In 1844, Heinrich Hoffmann refers for the first time, although in a more descriptive and literary way but support in his knowledge of Psychiatry, about a group of symptoms and characterized by restlessness and uncontrolled behaviors. Nevertheless, the first scientific approach come from Still, who claims in the Royal College of Medicine of the UK that exists a temporary or permanent defect in the moral control. His point of view is much more linked to genetic considerations instead of dysfunctional parenting styles. Still (1902: pp. 1008-1168) began to define the sample studied by the impulsivity, hyperactivity, antisocial or disruptive behavior, learning disabilities, struggle for the maintenance of attention, intolerance to frustration and pronounced emotional liability, among other aspects.

${ }^{4}$ Although we can follow the criteria for ADHD by the World Health Organization (WHO), inside the International Classification of Diseases (ICD) (10 $0^{\text {th }}$ Edition, 1992), we prefer to follow the Amercian Psychiatric Association (APA) for its adequacy to investigation. We can find the information in World Health Organization (WHO). See http://www.who.int/topics/mental disorders/en. Knowing with the full-named "International Statistical Classification of Diseases and Related Health Problems (ICD-10)” this WHO’s Manual contains guidelines for recording all kind of problems (illnesses) related to health.
} 
is established over the ones which were once named within the Behavioral Disorders. These were considered very important in the link to the subsequent antisocial conduct, to sum up, the worst results of the Attention-Deficit and Hyperactivity Disorder.

Particularly, with the meaning of Neurodevelopmental Disorders, we would mention the establishment of certain illnesses with more probability in certain stages of life and the possible continuity of this kind of disorders and/or their clinic characteristics in later stages, also noticing their possible co-occurrence. An example of this would be the affirmation of the co-occurrence of the Autism Spectrum Disorder with the Attention-Deficit and Hyperactivity Disorder. We also should match up that the New Edition of the APA gives an important role to the continuity of the clinical disorders, as we can see by the change of name in pathologies such as Schizophrenia, where the subtypes disappear to now talk about the Schizophrenia Spectrum Disorder and the conceptualisation of other illnesses that had a derogatory meaning and have now a more suitable social assessment (for example, Intellectual Disability instead of Mental Retardation).

We do not see as a contradiction the inclusion of the Attention-Deficit and Hyperactivity Disorder ${ }^{5}$ under the Neurodevelopmental Disorders with the extension of age from which the diagnosis of the illness could be introduced. We understand that this extension would come from the emphasis given to its possible presence in later stages of adolescence and adulthood.

As we said before, the relevance to focus on this issue concern to the fact of understanding ADHD as the most

\begin{abstract}
${ }^{5}$ We expose the diagnostic criteria for ADHD, where the only apparent difference from DSM-IV would be that all symptoms are followed by examples of different ways they may show up, including ways they would appear in older adolescents and adults. It can help clinicians to assess older adolescents and adults. Because symptoms can change over time, the presentation may change over time as well. Otherwise, we are going to do a more analytic and specific revision. More explanation about ADHD characteristics can be seen in DSM-5. According to the diagnostic criteria the diagnosis of ADHD will be defined as follows (APA, 2013: pp. 59-66): A. A persistent pattern of inattention and/or hyperactivity-impulsivity that interferes with functioning or development: 1. Inattention: Six (or more) of the following symptoms have persisted for at least six months to a degree that is inconsistent with developmental level and that negatively impacts directly on social and academic/occupational activities: Note: The symptoms are not solely a manifestation of oppositional behavior, defiance, hostility, or failure to understand tasks or instructions. For older adolescents and adults (age 17 and older), at least five symptoms are required: a) Often fails to give close attention to details or makes careless mistakes in schoolwork, at work, or with other activities (e.g., overlooks or misses details, work inaccurate). b) Often has difficulty sustaining attention in tasks or play activities (e.g., has difficulty remaining focused during lectures, conversations, or lengthy reading). c) Often does not seem to listen when spoken to directly (e.g., mind seems elsewhere, even in the absence of any obvious distraction). d) Often does not follow through on instructions and fails to finish school work, chores, or duties in the work place (e.g., starts tasks but quickly loses focus and is easily sidetracked). e) Often has difficulty organizing tasks and activities (e.g., difficulty managing sequential tasks; difficulty keeping materials and belongings in order; messy, disorganized work; has poor time management; fails to meet deadlines). f) Often avoids or is reluctant to engage in tasks that require sustained mental effort (e.g. schoolwork or homework; for older adolescents and adults, preparing reports, completing forms, reviewing lengthy papers). g) Often loses things necessary for tasks or activities (e.g., school materials, pencils, books, tools, wallets, keys, paperwork, eyeglasses, mobile telephones). h) Is often easily distracted by extraneous stimuli (e.g., for older adolescents and adults may include unrelated thoughts). i) Is often forgetful in daily activities (e.g., doing chores, running errands; for older adolescents and adults, returning calls, paying bills, keeping appointments). 2. Hyperactivity and impulsivity: Six (or more) of the following symptoms have persisted for at least six months to a degree that is inconsistent with developmental level and that negatively impacts directly on social and academic/occupational activities: Note: The symptoms are not solely a manifestation of oppositional behavior, defiance, hostility, or failure to understand tasks or instructions. For older adolescents and adults (age 17 and older), at least five symptoms are required. a) Often fidgets with or taps hands or squirms in seat. b) Often leaves seat in situations when remaining seated is expected (e.g., leaves his other place in the classroom, in the office or other workplace, or in other situations that require remaining in place). c) Often runs about or climbs in situations where it is inappropriate (e.g., in adolescents or adults, may be limited to feeling restless). d) Often unable to play or engage in leisure activities quietly. e) Is often "on the go" acting as if "driven by a motor" (e.g., is unable to be or uncomfortable being still for extended time, as in restaurants, meetings; may be experienced by others as being restless or difficult to keep up with). f) Often talks excessively. g) Often blurts out answers before questions have been completed (e.g., completes people's sentences; cannot wait for turn in conversation). h) Often has difficulty waiting turn (e.g., while waiting in line). i) Often interrupts or intrudes on others (e.g. butts into conversations, games, or activities; may start using other people's things without asking or receiving permission; for adolescents and adults, may intrude into or take over what others are doing). B. Several inattentive or hyperactive-impulsive symptoms were present prior to age 12 years. C. Several inattentive or hyperactive-impulsive are present in two or more settings (e.g. at home, school or work; with friends or relatives; in other activities). D. There is clear evidence that the symptoms interfere with, or reduce the quality of, social, school, or work functioning. E. The symptoms do not occur exclusively during the course of schizophrenia or another psychotic disorder and are not better explained by another mental disorder (e.g. Mood Disorder, Anxiety Disorder Dissociative Disorder, or a Personality Disorder, Substance Intoxication or withdrawal). Specify whether: Combined Presentation: if both Criterion A1 (inattention) and Criterion A2 (Hyperactive-impulsivity) are met for the past 6 months. Predominantly Inattentive Presentation: if Criterion A1 (inattention) is met but Criterion A2 (Hyperactive-impulsivity) is not met for the past 6 months. Predominantly Hyperactive-Impulsive Presentation: if Criterion A2 (Hyperactive-impulsivity) is met but Criterion A1 (inattention) is not for the past 6 months. Specify if: In partial remission: when full criteria were previously met, fewer than the full criteria have been met for the past 6 months, and the symptoms still result in impairment in social, academic, or occupational functioning. Specify current severity: Mild: Few, if any, symptoms in excess of those requires to make the diagnosis are present, and symptoms result in no more impairments in social or occupational functioning. Moderate: symptoms or functional impairments between "mild" and "severe" are presented. Severe: many symptoms in excess of those required to make the diagnosis, or several symptoms that are particularly severe, are present, or the symptoms result in marked impairment in social or occupational functioning.
\end{abstract}




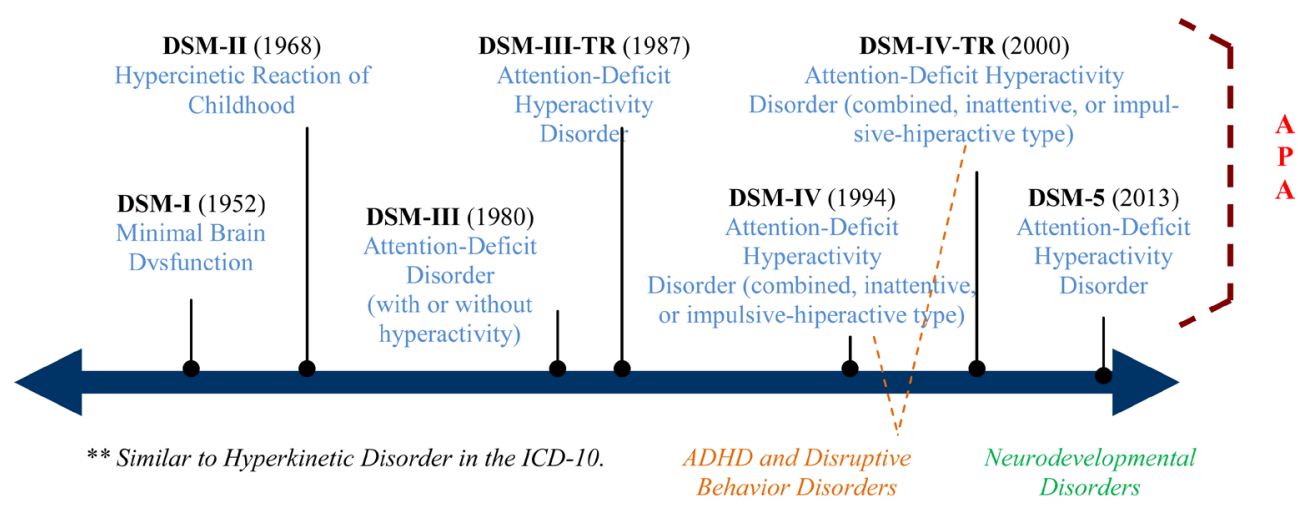

Figure 2. Evolution in the consideration of ADHD by the APA over the years (Aguilar Cárceles, 2014: p. 72).

prevalent Neurodevelopmental Disorder worldwide. Its nuclear symptomatology is established by lack of attention, hyperactivity and impulsiveness, that means, as a Neuropsychiatric or Neurobehavioral disorder defined by the levels of deterioration of the lack of attention, organization, and/or presence of hyperactivity and impulsiveness and that intercedes in the function and development of the individual with an important impact or enough clinic meaning, all of it justified by its early beginning and possible permanence afterwards.

Once said that, to the assessment of these results it is essential to study the characterization of the disorder during childhood, adolescence and adulthood as well as assess the description in the main reference International Handbooks, the Diagnosis and Statistical Manual of Mental Disorders (DSM). That is why we consider important to talk about the continuity of the Attention-Deficit and Hyperactivity Disorder, its identification and characteristics: prevalence, diagnostic criteria and symptoms in the different stages of life.

Continuing with the explanation, the DSM-5 broadens the age range in which the Attention-Deficit and Hyperactivity Disorder can be estimated from 7 to 12 years. The possibility of diagnosis is benefited and, where applicable, the overrepresentation of the illness. It is also specifically indicated that its symptomatology could be very complex to diagnose before 4 years. This new characterisation of age could turn out to be incoherent if we pay attention to the fact that its new location under the Neurodevelopmental Disorders, why should we broaden the age range if it is within the frame of the illnesses of early diagnosis and this precocity would be emphasised? The truth is that the answer to this question would be seen from the opposite point of virew, it is said, appreciating that its breadth to older ages would be in favour of what in the Text is more evident in the last Edition, the specific mention to adulthood, symptomatology continuity and consequences from the group of psychopathologies under the mentioned frame. The more important role given to the continuity of the illness in later stages would be justified, the same as the use of the term spectrum more often.

This rate in the first years is calculated around 5\% (Soutullo Esperón \& Díez Suárez, 2007) ${ }^{6}$, for instance, Kolar, Keller, Golfinopoulos, Cumyn, Syer and Hechtman confirms that "ADHD is prevalent neurobiological condition, affecting $4.4 \%$ of the general population. It is accompanied by high rates of comorbidity (depression, anxiety, substance abuse) and significant social, emotional, and occupational impairments, which affect the patients and their families" (2008: p. 401). However, some study research indicates that this percentage could be higher estimating a world percentage of 5.3\% (Polanczyk, De Lima, Horta, Biederman, \& Rohde, 2007) or even 85 - 12\% (Minzenberg, 2012).

In the DSM last Edition, adulthood is specifically mentioned with the inclusion of examples in the diagnosis criteria and its possible prevalence in adulthood is specified in $2.5 \%$ by APA, although some authors consider a bit higher this percentage (Faraone, Biederman, Spence, Wilens, Siedman, Mick, \& Doyle, 2000). In general terms, we must considerer that general prevalence of ADHD decrease with the years (Simon, Czobor, Balint,

\footnotetext{
${ }^{6}$ This percentage was obtained by some authors as Soutullo Esperón and Díez Suárez (2007) who, after informed that ADHD could affect between $2 \%-12 \%$ of pediatric population, affirm that the average would be in the $5 \%$. The same percentage is found by Halmoy, Klungsoyr Skjaeren and Haavik (2012) who indicate that is the most prevalent disorder in childhood over the world. In spite of that, further investigations refer a higher prevalence, even $8 \%$ or $12 \%$ (Polanczyk, De Lima, Horta, Biederman, \& Rohde, 2007). Likewise, neither subtypes of ADHD would present similar percentages, having different consequences depending if the subtype is inattentive or not. Particularly, inattentive subtype refers more problems in the educational level while hyperactive and impulsive signs are more related to behavioral problems (Wolraich, Hannah, Pinnock, Baumgaertel, \& Brown, 1996).
} 
Mészaros, \& Bitter, 2009), moreover, only a percentage of $40 \%$ of this $2.5 \%$ will have a worse and severe prognosis (Young, Adamon, Grudjonsson, Müller, Pitts, Thome, \& Asherson, 2011) mainly due to the genetic determination (Franke, Faraone, Asherson, Bitelaar, Bau, Ramos-Quiroga, Mick, Grevet, Johansson, Haavik, Lesch, Cormand, \& Reif, 2012). In relation to gender in adulthood, its manifestations can show similar symptomatology —not in the presence of the Disorder, not finding differences according to gender (Barkley, Murphy \& Fischer, 2008).

The external symptomatology is more prevalent in boys (San Sebastián Cabases et al., 2010) and it diminishes the difference of estimated proportion of the illness among genders according to their age with 2:1 in the first years and 1.6:1 in adulthood, always more proportion in boys (APA, 2013; López Soler, Belchí, \& Medina, 2013). In spite of that, we should underline that the presence of internal symptomatology is bigger in girls but it does not mean that they will not suffer consequences equal to or more than the masculine gender. According to this, we match up that the motor symptoms of hyperactivity could be less obvious in adolescence and adulthood keeping the difficulties related to anxiety, lack of attention, poor planning and impulsiveness. Specifically, Ward, Wender and Reimherr (1993: p. 885) indicate that a good diagnosis in adulthood should contemplate the following seven aspects: 1) lack of attention, hyperactivity; 2) impulsivity; 3) emotional lability; 4) irritability and bad temper, 5) poor stress tolerance, 6) disorganization, and 7) impulsivity ${ }^{7}$. Furthermore, as we expose later, poor planning joined to this last characteristic will be the most engaged symptoms related to later stages and process of the illness (e.g. comorbidity).

Anyway, according to Gratch (2009), the name of ADHD in adulthood respond to residual type referred to the unnecessary manifestation of all the characteristic symptoms of the ADHD described in DSM. In this sense, neither all the symptoms $\mathrm{n}$ or in the same way will be present in adulthood, meaning presentation in a different modality depending of the life-span period. Furthermore, this does not necessarily mean that we can do ADHD adult retrospective diagnosis (Zucker, Morris, Ingram, Morris, \& Bakeman, 2002), in these cases, we should consider a range of characteristics once it was already diagnosed in childhood, such are workplace adaptation and driving (Ramos-Quiroga, Bosch-Munsó, Castells-Cervelló, Noguera-Morais, García-Giménez, \& CasasBrugué, 2006).

\subsection{How Far Should Be the Symptomatic and Syndromal Continuity to Result in Antisocial Behaviors?}

Following the previous point, we can say that the true important issue in the link of the Attention-Deficit and Hyperactivity Disorder to criminality would come from observing the permanence of the symptomatology of the illness more than the disorder itself because is exactly the external symptomatology the one that with more probability in this relation the lack of attention will be the most lasting symptom. In this context, in the proportion of infants that could suffer from the ADHD in adulthood, there would be a minority whose characteristics would be hyperactivity and impulsiveness, symptoms that, in our opinion, the DSM should name and describe separately due to the characterization and consequences originated from each of them so that impulsiveness is exclusively the one related to criminality and not hyperactivity ${ }^{8}$. That would also explain its co-occurrence with other psychopathologies such as Oppositional Defiant Disorder, Conduct Disorder, Substance-Related and Addictive Disorders or Disruptive, Impulsive-Control and Conduct Disorders.

From the most important aspects of the previous information comes the necessity of answering different questions: to what extent could we talk about the continuity of the disorder? Would it be better to admit a symptomatological continuity? Which would be the most related symptom to the continuity of the Attention-Deficit and Hyperactivity Disorder and which is leading to its worst consequences? Would the extrapolation of the diagnosis criteria be suitable for its diagnosis during adulthood? If it is a Neurodevelopmental Disorder which diagnosis occurs during childhood, how could the ambiguity of its presentation in the DSM mislead the possible diagnosis at this stage?

As we mentioned, the most lasting symptoms are the ones related to lack of attention, following impulsive-

\footnotetext{
${ }^{7}$ Further information in alternative articles such is Ward, M., Wender, P.H. \& Reimherr, F.W. (1993). The Wender Utah Rating Scale: An aid in the retrospective diagnosis of children with ADHD. American Journal of Psychiatry, 160, 245-256.

${ }^{8}$ However, if we appreciate their descriptions by APA, they are considered indivisible and interrelated. It is quite obvious, and as DSM describes by examples they are not the same, but if the real chronicity in its relationship to antisocial behaviuor come from impulsiveness, why are not they separated?
} 
ness and hyperactivity-the least chronic symptom (Biederman, Mick, \& Faraone, 2000; Ramos-Quiroga, Bosch, \& Casas, 2009). However, the question to the previous would focus on understanding that the majority of the mentioned illnesses are diagnosed in later ages or otherwise, the Attention-Deficit and Hyperactivity Disorder will not be diagnosed from 12 years so that when in adults we suppose the existence of the disorder that could explain the link to later Oppositional Defiant Disorder and Conduct Disorder, and the risk of criminality would be based on this diagnosis made in early stages because in another way we could not understand the link.

Once again, the scientific literature is controversial when establishing concrete ages for the diagnosis. The DSM sets examples of behaviors that could be linked to the adult with Attention-Deficit and Hyperactivity Disorder, reason for which exclusivity would be understood as durability of an illness that had already been diagnosed. In spite of that, how could we talk about diagnosis in childhood if the Handbook of the APA says that for adolescents and adults (older than 17) the request of the described diagnosis criteria would be reduced to five types of attention and/or hyperactivity-impulsiveness? In this context, some authors talk about the suitability of the diagnosis criteria of the APA to set the Attention-Deficit and Hyperactivity Disorder in adults but, should we match this statement up to talk about criteria that could reflect the continuity and not the diagnosis? In the end, we would talk about a lingering type of Attention-Deficit and Hyperactivity Disorder but that stipulated under the same or similar criteria as the demanded for the diagnosis in childhood would not be suitable, moreover, we admit that the concretion would not be probable without admitting the diagnosis before 12 . The statement of the APA could look incoherent, not due to the examples that link the illness to adulthood (work impact, worse relationships, interruption, car accidents, comorbidity with Substance-Related and Addictive Disorder and Personality Disorder, etc.) but for permitting to talk about diagnosis instead of continuity.

This is a neurobiological condition that would be differentiated not only for the quantity of its presence but for the symptom qualification. The nuclear symptomatology of the illness permits to outline possible future paths of the individual more than the diagnosis itself. In this context, the evolution of the Attention-Deficit and Hyperactivity Disorder is changeable according to the stability of the lack of attention symptomatology (Figure 3). This would be the one which lasts longer although the combined subtype is the most frequent, so we dare to say that the chronification of the illness would depend more on the symptomatology than on the type of the Attention-Deficit and Hyperactivity Disorder that would also justify the alleviation of the symptoms of hyperactivity. Thus, the majority of behavioral symptoms in adults are the ones related to the lack of attention, included under the predominant inattentive type or under the combined one (Hurting, Ebeling, Taanila, Miettunen, Smalley, McCough, Loo, Marjo-Rittaja, \& Moilanem, 2007; Wilens, Biederman, Faraone, Martelon, Westerberg, \& Spencer, 2009).

Relative to the Disorder itself, it is affirmed that $50 \%$ - 70\% of the children would still suffer from the illness in adolescence and between $25 \%$ - $40 \%$ in adulthood, only a quarter of them with the most severe consequences (Loro López, Jiménez Gómez, \& Quintero Gutiérrez del Álamo, 2009)9. While a third of children with Attention-Deficit and Hyperactivity Disorder will not show it during adolescence, another third will stop from suffering it during adulthood and another third will remain ill. Some of them would keep the symptoms but not the complete illness, this is why it is considered a chronic, long-term problem (Soutullo Esperón, 2008). To sum up,

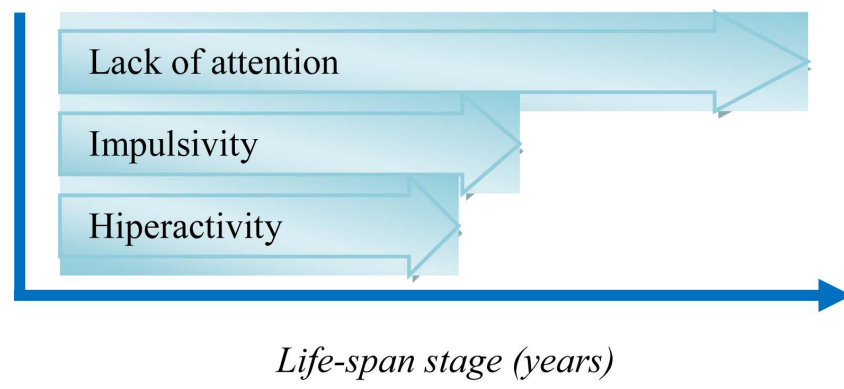

Figure 3. Example of the evolution ADHD symptoms evolution Ramos-Quiroga et al., 2009: p. 18).

\footnotetext{
${ }^{9}$ In that sense, other longitudinal investigations refer that the Disorder could be continued in the $15 \%$ of subjects in the following 25 years, even with the $50 \%$ of the maintenance of the dysfunctional symptoms (McCarthy, Asherson, Coghill, Hollis, Murray, MPotts, Sayal, De Soysa, Taylor, Williams, \& Won, 2009; Young, Fitzgerarld, \& Postma, 2013). On the other hand, other authors indicate that this percentage could be higher, until 70\% (Silver, 2000).
} 
it could be understood as a risk factor, ADHD as an evolutionary risk factor to antisocial behaviuor and ulterior criminality (Parellada Redondo, 2009).

It is necessary to distinguish the presence of the full Disorder from the presence related with this. In this point, we must emphasize the fact of not being the same the persistence of the Disorder and the persistence of some symptoms (descriptors) of the Disorder ${ }^{10}$. According to that, Derks, Hudizak and Boosman (2009) indicate that persistence of the diagnosis over the years is low in comparison with the continuity of symptomatology (Derks, Hudizak, \& Boomsma, 2009). It could explain why the derivation to other mental disorders related to ADHD.

This is why we could not admit that the alleviation of the illness would lead to the alleviation of symptoms nor the following problems, general prevalence of the disorder that also the APA reflects in a larger flexibility and less required rigidity according to the foreseen criteria for adulthood. Therefore named as lingering ADHD, because of the recognition of persistence but questioning the suitability of the established criteria, the validity of the extrapolation of the diagnosis criteria from childhood to adulthood, would not be evolutionary suitable. Moreover, the concretion of the ADHD in adulthood would not be possible without the existence of this in childhood, that would be a necessary condition for the perpetuity of such diagnosis in adulthood that had been retrospectively observed and diagnosed in the first years of life. We would underline that the Disorder does not maintain itself, only a determined symptomatology derived from a diagnosis in childhood and appeared in adulthood is going to emerge as a consequence of the ADHD, since other disorders could be considered responsible of it, so that we should distinguish the existence of co-occurrence or explanatory frames of impulsive symptomatology by themselves. An example of this would be the appearance of symptomatology related to the ADHD, without diagnosis of it in childhood should not be named exactly as disorder but from other that share similar symptomatology, such as the case of the impulsiveness showed in an individual with Bipolar Disorder in the manic phase.

The Diagnostic and Statistical Manual shows important limits in the concretion of the ADHD, it would be correct to affirm that the DSM offers only an illustrative guide regarding the determination of the persistence of the diagnosis in adulthood when the clinical criteria in this population are more heterogeneous, delicate and imperceptible showing that the diagnosis should contain a range of more diverse and specific symptoms so that we can talk about continuity at this age. Currently, there has been a reduction of the severity of the required threshold and a reduction of the number of the symptoms required for its clinical reconfirmation in five adolescents from 17 and adults.

There is an evident heterogeneity of symptoms when we talk about adulthood requiring the DSM a larger list of situations and conceptualizations than the one used now, moreover, as I mentioned before, I would say that the suitability of considering independent sections-apart from the understandable for other stages-, mainly justified because there is no possible diagnosis in adulthood but its persistence, supported now by the mistake of using similar criteria-although new aspects have been introduced. To sum up, the hypothesis on the suitability of the extrapolation of the symptoms lack of attention, hyperactivity and impulsiveness which used in childhood could define the adult with ADHD, would be negative, but not the majority of significant items for the definition of the disorder in this group. In spite of the previous, the DSM would reflect the poor trust that adult information regarding the assessment of the criteria could transmit.

\subsection{Impulsivity as the Major Risk Factor}

From the previous point and regarding the idea of impulsiveness, the main critic comes from the description for each symptom and its wrong similarity with hyperactivity starting with the own evolution of both terms that would be different. This way, in the 9 characteristics what define the group of external symptomatology in the Attention-Deficit and Hyperactivity Disorder (hyperactivity-impulsiveness) only 3 regard to impulsiveness, the link to the Attention-Deficit and Hyperactivity Disorder with crime, when the presence of the last one in an exclusive way would be more difficult. Regarding this, a reasonable explanation could be the fact of understanding the items that normally measure the anxiety or other ways of hyperactive behavior which lead to factors that show impulsiveness or uninhibited behavior. Due to this, the confusion originated in the literature as well as in the empirical research based on the external symptoms of the Attention-Deficit and Hyperactivity Disorder. It is here where I understand that the Handbook could distinguish a symptom and the external symptomatology in a

\footnotetext{
${ }^{10}$ The fact that the Disorder does not exist by itself do not mean that we do not find some specific consequences linked to symptomatoloy
} that produce disturbance in the person. 
more specific way, mainly because of the possible consequences that could come from the presence of one and another element, because currently it is not possible to diagnose Attention-Deficit and Hyperactivity Disorder exclusively about impulsiveness.

Impulsiveness as main element regarding the objective of the Dissertation would be defined as a quick answer, excitement, unthinking act, lack of inhibition of impulses or behavior, or the incapacity to delay the response, among other aspects (Barkley, 2006). We could understand that there is an absolute lack of inhibitory control but that would not be admitted. The inhibitory effect would act as a motivational basis for the action, that is, a control or restriction from the behavior itself would exist when there is a reward. As Sonuga-Barke (2005) indicates, regarding to the basics of the knowledge of the individuals on their own actions, the one with Attention-Deficit and Hyperactivity Disorder would have the capacity to modify the action when there is a future reward. In this sense, they are even able to plan actions according to special interests.

Moreover, it is above this cognitive style or aptitude element when we can precise that not all the consequences are negative but that in determined situations there could be a harder performance in impulsive individuals, better accuracy and response from them to groups of control (Pedrero Pérez, 2009). In a specific way, we can obtain more precise solutions by understanding that they are able to control their level of impulsiveness and be aware of the consequences of their actions. This is very important for the later requirements about the demand of responsibility in order to the consequences of their actions.

It is true that they have difficulty to comply with the rules-standards and limitations in spite of knowing that, even they are able to show repentance, although it can be diluted over the time and be a sign of worse prognosis (Quintero, Herrera, Correas, San Sebastián, García, \& Loro, 2009).

There would be a type of behavioral control where individuals with Attention-Deficit and Hyperactivity Disorder could adopt certain strategies according to the initial motivations, from which not only the possibility of control can be deduced but also the planning capacity when there is a stimulus as result. The problem would be presented according to the temporal element, that is, the impossibility of acting coherently due to a late planning or an uncontrollable impulsiveness. Nevertheless, we should be careful about this when the DSM indicates that impulsiveness would be defined as the action in response to an immediate stimulus acting above the basis without planning or considering the results, with difficulties for establishing and following plans, with feeling of urgency and Self-Injury behavior in stress situations.

The question to the previous would result from affirming that there is a control of the conduct justified in obtaining a gratifying result, that would conclude in the capacity of self-management of the own conduct.

In any case, impulsiveness would be defined as a risk factor at the beginning and development of the later criminal path. It is especially problematic when linked to the development of other pathologies, intake of substances, car accidents, and reckless conduct ${ }^{11}$. This predisposition to quick or impulsive actions could be understood as a characteristic and not a condition, a tendency that would not mean an absence of knowledge about the actions.

The purpose of not damaging, the poor capacity to inhibit impulses (at cognitive and behavioral level), the difficulty to obey the Law and limits despite knowing it, not thinking previously, the appearance of physical attack when they are altered, would be defining aspects of a subject with Attention-Deficit and Hyperactivity Disorder that could be controlled in certain situations in particular when the action is followed by a beneficial result. Moreover, the intention of damaging would not be included in the description of the illness. When they do it, they feel bad about it, the regret would appear, that would mean knowledge about the action and judgement of the suitable action from the socially unsuitable (Aguilar Cárceles, 2014).

From this, we understand that if the regret exists, the knowledge about the action and if it is socially appropriate does exist too. If we are talking about a cognitive style or special characteristic of the individuals and knowing that the intention to damage is not a characteristic of the description of this illness but of others, this does not mean that in certain moments this intention would not be perceptible.

All of this would be translated into a poor learning of self-control and an impulsive behavior in certain situations, concluding the possibility to motivate the change of action when the ability is trained and, therefore, self-regulation.

\footnotetext{
${ }^{11}$ Mainly due to the lack of impulse control and failure in the control of several tasks (e.g. it can results in a major number of car crash and reckless driving). Even, in a worse educational achievement and social adjustment, overall if the present comorbidity with other psychopathologies (Ramos-Quiroga, Bosch-Munsó, Castells-Cervelló, Noguera-Morais, García-Giménez, \& Casas-Brugué, 2006).
} 
It is clear that the explanation of the modified pattern of the Attention-Deficit and Hyperactivity Disorder is established according to the life-span development of the child to inhibit arrogant answers, change patterns of response and control interferences which would be translated as an important behavioural lost of inhibition. Thus, the incapacity of motor control or the absence of enough inhibited desire, will end in a process of modified and unsuitable self-regulation, consequence of the variation, among others, of the capacities related to the action. In this context, the research and study of the factor impulsiveness will have special importance before hyperactivity and lack of attention, even though it will be from external symptomatology the one from which the link to criminality is worked out, hyperactivity will not be as worthy as impulsiveness at this moment.

This is the reason that from the research on the characterization of the disorder we could talk about certain symptomatology that, as a risk factor, links the Attention-Deficit and Hyperactivity Disorder to the criminal path. This relation, as we will see during the text, will happen especially in a small portion of individuals. However, the previous statement would be nuanced according to the exclusion of a right, not confusing, early detection with which we could treat the initial symptomatology of similar illnesses.

\section{Some Biological and Neurochemical Aspects}

The emphasis given to the Attention-Deficit and Hyperactivity Disorder linked to the idea of Neurodevelopment is clear due to its beginning and appearance in the first stages of life, the moment in which we give a lot of importance to the biological factors in the explanation of the origin of the illness ${ }^{12}$. Therefore, it is necessary to analysis this kind of conditions from a genetic basis, neuroanatomy, neurophysiology and research on neuroimaging to finish examining the aspects related to neurochemical and pharmacology agents. The assessment of the effects of the ADHD must consider both psycho-biological and social factors in the development of antisocial and criminal conducts. Although we recognize ADHD as a multidimensional Disorder with importance to biological conditions, we could not forget that the external factors will play a key role in determining its path (Schachar \& Tannock, 2002).

Although we do not know the main cause of the disease, it is obvious that the high component which identifies it at biological level allows us to give importance to this kind of conditions, admitting the vulnerability and genetic, anatomic, functional and neurochemical predisposition opposite to the individuals who do not suffer from the illness (Schachar \& Tannnock, 2002; Soutullo Esperón \& Díez Suárez, 2007). The questions that arise from it would be established on the suitability of the genetic code and anatomical differences in the diagnosis of the Disorder and the factors that, at this level, could predict the ones for whom is going to be chronic and continuous. In addition, it is not only interesting to know if certain alleles and genetic locus will be able to advise about the remaining of the disorder but it is also interesting to know how we can reduce the effects and control the consequences at neurochemical level.

The presence of several biological deficits is obvious according to the empirical finds obtained about the biological aspects of the Attention-Deficit and Hyperactivity Disorder, which does not reject the heterogeneous etiology of the illness. For example, Rettew and Hudziak (2010) say that ADHD would be a set of very prevalent and heritable genetic illnesses, the problem of its heterogenic etiology continue being the main limit to save in order to know which genes are responsible for the ADHD (Sprich, Biederman, \& Crawford, 2000; Comings, 2001; Soutullo Esperón \& Díez Suárez, 2007), what let us to say that this mental pathology "is one of the most heritable disorders” (Minzenberg, 2012: p. 611).

Anyway, it does not mean that genetic factors will be the unique ones that affect the continuity of the Disorders, they are going to get worse the symptoms, but they are not a cause enough to provoke the Disorder.

In this sense, the multidimensionality of the Attention-Deficit and Hyperactivity Disorder-focusing on its more significant symptoms of lack of attention and impulsiveness and the consequences of these alterationswould deny admitting the meaning of "normality" for whom represents it, finding a lot of differences related to the normalized population groups. Therefore, the problem would be based on the absence of an enough inhibiting will, a lack of control of impulses, an incapacity of adjust the action, being a real problem of the chemical dynamics of the brain.

Thinking about a minor neurological symptomatology marked by the lack of self-control, anxiety or impul-

\footnotetext{
${ }^{12}$ Recent research studies on heridability (genetic maps of ADHD) by King's College—Social, Genetic \& Developmental Psychiatry Centre (MRC) — support this risk based on the high prevalence that nowadays is diagnosed ADHD.

https://www.kcl.ac.uk/ioppn/news/records/2015/november/brain-patterns-adhd-bipolar-disorder.aspx
} 
siveness, and in spite of the biological origin, this would not allow us to talk about a single particular mechanism at brain level, but that the complexity of the diagnosis comes from a variety of etiology facts, mechanisms, symptomatic superposition, comorbidity and changes in the development that could be considered as normal or without clinical meaning according to the influence of environmental factors. In spite of that, nowadays it is confirmed that "the biological conditions are more significant in terms of vulnerability or tendency" (Popper, Gammon, West, \& Bailey, 2003: p. 844), although the specific etiology cause of the Attention-Deficit and Hyperactivity Disorder is still unknown.

More specifically, according to the biological conditions, we should talk about a multigenic disorder based on the multifactorial model of multigenic inheritance, which risk of heredity—not appearance-would be between 30\% and 70\% (Cortese, Faraone, \& Sergeant, 2011; Frank et al., 2012). Moreover, the behavioral lack of inhibition would be the most likely to inherit, reaching the 84\% (Young, Stallings, Corley, Krauter, \& Hewitt, 2000). This could have very important meanings to be related with other illnesses such as Oppositional Defiant Disorder and Conduct Disorder, use of drugs, and Personality Disorders, among others.

At genetic level, the risk of the Attention-Deficit and Hyperactivity Disorder in genetic carrier of dopamine such as DAT1 and DRD4, in determined locus, would increase together the risk of appearance of these disorders (Soutullo Esperón \& Díez Suárez, 2007), although they only add an additional risk ${ }^{13}$. This is why the appearance of Attention-Deficit and Hyperactivity Disorder would depend on the probability of appearance of duplicate or lost segments of DNA, which are genetic variation also found in Autism and Schizophrenia (William, Zaharaieva, Martin, Langley, Mantripragada, Fossdal, Stefansson, Magnusson, Gudmundsson, Gustafsson, Homans, Oewn, O’Donovan, \& Thapar, 2010). According to this, there is an evidence of an essential superposition among genetic risk factors shared with the Bipolar Disorder, Depression and Schizophrenia to which Autism and the Attention-Deficit and Hyperactivity Disorder are linked (Popper et al., 2003) ${ }^{14}$. Nevertheless and in spite of the possible convergences referred to the biological aspect between Attention-Deficit and Hyperactivity Disorder and Schizophrenia, from the APA it is affirmed that there is an impossibility of diagnosis co-occurrence when the symptoms of the Attention-Deficit and Hyperactivity Disorder exclusively happen in the process of a Schizophrenia Spectrum and other Psychotic Disorders.

Regarding the question if there will be the same genes or not the genes that would influence in the continuity of the disorder, we admit that the same genes would be the ones which would be part of the different stages of the development but they would differ from others depending on the appearance of their alleles (Cortese, Faraone, \& Sergeant, 2011). It has been confirmed that there would be certain locus associated with the appearance of the illness along life, not understanding the exact function. Moreover, the study of research related to meta-analysis allows us to appreciate evidence of differences about the predisposition of the lasting Attention-Deficit and Hyperactivity Disorder opposite the Attention-Deficit and Hyperactivity Disorder in childhood.

According to the previous lines, a genetic susceptibility does exist and only a part of the diagnosis would remain in adulthood. It would be suitable to talk about different genetic appearances that would guarantee continuity. This way and before the question about if the genetic explanation of the Attention-Deficit and Hyperactivity Disorder would be the same in childhood and adolescence as the one of the lingering Attention-Deficit and Hyperactivity Disorder, it could be appropriate to confirm that the appearance of the Attention-Deficit and Hyperactivity Disorder in adulthood shares genetic factors of susceptibility with the expression of the illness in childhood, but maybe we should investigate if some of the genetic risk factors that have been presented could be specific of the age. This way, the chronic aspect of the Attention-Deficit and Hyperactivity Disorder could be benefited opposite to the symptomatology disappearance which could be seen in most of the cases during late childhood and adolescence.

In the same way, the disturbances are found not only at genetic level but also at neuroanatomical and functional, that would be the case of the volume reduction of the cortex (Filipek, Serud-Chilikeman, Steingard, Renshaw, Kennedy, \& Biederman, 1997) the caudate nucleus (Castellanos, Giedd, Berquín, Walter, Sharp, Tran, Vaituzis, Blumenthal, Nelson, Bsatain, Zijdebons, Evans, \& Rapoport, 2001) or cerebellum (Popper et al., 2003) leading to notice that although for the first cases the diminishing of the brain volume could be normal in adulthood (Castellanos, Lee, Sharp, Jeffreis, Greenstein, Clasen, Blumenthal, James, Ebens, Walter, Zijdenbos,

\footnotetext{
${ }^{13}$ More information in http://www.kcl.ac.uk/iop/depts/mrc/research/adhdgen/adhdgeneticsgroup.aspx

${ }^{14}$ Further information about this topic in: Cross-Disorder Group of Psychiatric Genomics Consortium (2013). Genetic relationship between five psychiatric disorders estimated from genome-wide SNPs. Nature Genetics, 45, 984-994.
} 
Evans, Giedd, \& Rapoport, 2002), that would not happen in the case of the cerebellum. Thus, if we link the action functions of motor control and mobility and behavioral inhibition (Shaw, Evans, Eskstrand, Sharps, Blumenthal, Greenstein, Clasen, \& Giedd, 2007), maybe a suitable structure to explain the continuity of the Attention-Deficit and Hyperactivity Disorder could be this part of the Central Nervous System.

One hypothesis to answer would be address to the question on if it would be the reduction of the volume of the front areas, basal ganglia and cerebellum what would benefit the Attention-Deficit and Hyperactivity Disorder, or the diminishing would be a simple reflect of the underlying processes. Today we cannot yet affirm that that the specific changes would be the consequences of the Attention-Deficit and Hyperactivity Disorder, but underlying factors of the neurodevelopment that would benefit the presence of its symptomatology.

We do not avoid the role of the prefrontal cortex, regarding the malfunctions that characterises at this level the appearance of the Attention-Deficit and Hyperactivity Disorder, mainly in the relation to execution, planning of tasks and inhibition of actions. It is detected functional abnormalities in the areas related to actions, a disturbance due to a hypodopaminergic status of the prefrontal cortex that would produce the deregulation of the condition of neurochemical balance resulting in the symptomatic expression of the Attention-Deficit and Hyperactivity Disorder, which would have different neural basis depending on the predominant symptomatology it shows (Solanto, 2002).

In spite of that, at neuroanatomical level it is confirmed that the brain maturing of infants with Attention-Deficit and Hyperactivity Disorder is normal when they reach a pattern of normal development in certain brain areas, not indicating this that the rhythm or chronology of acquisition would be suitable. There is a delay in the development of certain regions being more prominent at frontal level and, in some cases, in temporal level (Shaw et al., 2007). There is a normalized pattern of cortex maturing (brain plasticity and biological possibility of adaptation), which would support the hypothesis of the symptomatology decreasement after some years, moreover, we could specify adolescence as the moment in which more development and similarity among individuals with Attention-Deficit and Hyperactivity Disorder and control groups are reached, denying that the Attention-Deficit and Hyperactivity Disorder is a brain atrophy (Pueyo-Benito, Mañeru-Zunzarre, Vendrell-Gómez, Mantaroa, Estévez-González, García-Sánchez, \& Junqué, 2000).

The research on image help us to know the presence of one Disorder (Sowell, Thompson, Welcome, Shenkenius, Toga, \& Peterson, 2003; Bansal, Staib, Laine, Hao, Xu, Liu, Weissman, \& Peterson, 2012), but in the case of ADHD we must consider the delay in the development of the cortex as a sign but we could not confirm the diagnosis of the Attention-Deficit and Hyperactivity Disorder in a concrete individual from this technique. We could admit that the images of brain neuroanatomy would ensure the diagnosis of chronic psychiatric pathologies or other illnesses empirically contrasted (Insel, 2010).

The exact mechanisms could mainly come back to be unknown, suggesting the majority of research the possible abnormalities in the neurotransmission systems, even, as Krain and Castellanos indicate, "depending of this kind of substrates we find the different variations of ADHD" (2006: p. 441). More specifically, the main discoveries about the etiology of the Attention-Deficit and Hyperactivity Disorder have focused on the research on genes related to the path of catecholamine and more recently, giving special importance to the serotonin hypothesis. There is a concrete abnormal activity of certain chemical substrates in the prefrontal cortex córtex prefrontal which collaborates with the appearance of the Attention-Deficit and Hyperactivity Disorder. Specifically, the illness appears when there is a genetic variation in the coding of certain neurochemical agents linked to dopamine and norepinephrine (Biederman \& Spencer, 1999; Comings, Gade-Andavolu, González, Wu, Muhleman, Blake, Dietz, Saucier, \& MacMurray, 2000).

There is a hypoactivation or reduced functioning in areas such as the frontal cortex, the caudate nucleus and cerebellum. The person with Attention-Deficit and Hyperactivity Disorder secretes a smaller quantity of noradrenaline where the falls to optimal levels at a prefrontal level will have effect on the good function. We have also discovered small concentrations of serotonin in children with Attention-Deficit and Hyperactivity Disorder describing it as a neurotransmitter that helps the inhibition of the impulsiveness, hyperactivity and aggressiveness (Barrickman, Noyes, Kuerman, Schumacher, \& Verda, 1991; Spivac, Vered, Yoran-Heges, Averbuch, Metser, \& Graf, 1999). According to this, it is not strange that the malfunction in these levels would have been possible in pathologies such as the Oppositional Defiant Disorder and Conduct Disorder (Barkley et al., 2009). In this way, the unbalance in the interaction between the systems of neurotransmission (dopaminergic and serotonergic) would be considered as a key intermediary in the appearance of the Attention-Deficit and Hyperac- 
tivity Disorder, to which we also link the patterns of violent behavior and the biological substrates could reach to be common to Antisocial Personality Disorder and Substance-Related and Addictive Disorder ${ }^{15}$.

The question of the pharmacology of the Attention-Deficit and Hyperactivity Disorder appears about the use of drugs such as MTF (psychostimulant) and ATX (non-stimulant) which are commonly used for the treatment of the illness (Faraone, Biederman, Spencer, \& Aleardi, 2006). Traditionally, the first has been used with this diagnosis but, would it be advisable for all ages? Would there be a possibility of benefiting the development of mental disturbances after consuming them? This is exactly one of the most discussed questions to a possible consequence of a long term consumption of stimulants for a diagnosis of a disorder related to substances and addictions. In any case, we can see that the stimulating drugs have been and keep on being the predominant treatment.

The pharmacodynamic of the stimulating treatment prescribed in patients with Attention-Deficit and Hyperactivity Disorder increases the quantity of dopamine and noradrenaline available in the neuron synapse when the mechanisms of specific action are the ones which would include the block of the transporters of both neurotransmitters, the inhibition of monoamine oxidase and the increase of the release of catecholamine from the presynaptic cells (Barrickman, Noyes, Kuerman, Schumacher, \& Verda, 1991). The concentration of these neurotransmitters is increased so that its availability is wider in the organism and would act improving the function. Among them, MTF and ATX have been the psychostimulant and non-stimulant drugs commonly prescribed. The main argument and reticence to the use of the first one the possibility of becoming a Substance-Related and Addictive Disorder. It is a widely rejected statement by most of the researchers, justifying not only the absence of this link but also the protective effect of the consumption of psychostimulants in infants with Attention-Deficit and Hyperactivity Disorder to the later use of drugs (Loney, 1998; Biederman, Wilens, Mick, Spencer, \& Faraone, 1999). Anyway, following what the National Institute for Health and Care Excellence (NICE) confirms, the ideal will be a choice according to the necessities of the patient ${ }^{16}$.

To sum up, the importance of the biological factor in the definition of Attention-Deficit and Hyperactivity Disorder becomes even more relevant since 2013, when its location goes with the group of the so called Neurodevelopmental Disorders in the DSM-5.

\section{The Most Relevant External Risk Factors to Explain Criminality}

Leaving apart the previous point, other new aspects introduced by the APA is the fact that they leave an independent section to talk about the risk and protection factors when under this sign the separation of the features regarding temperament, genetics, environment and physiology is established. The convergence of these features is the one from which we can talk about the criminal path.

\subsection{Is It Possible to Explain Criminal Career Attending to a Particular Factor?}

After appreciating biological factors, starting now with the influence of psychosocial factors and giving special meaning to them in the framing of the illness, we are going to analyze the influence from social factors of equal or more importance, such are the influence of styles of education, number of brothers and sisters, abuse record, criminal parents, social group, neighborhood or community, among others. Particularly which concerns to hyperactivity and impulsivity such as individual factors, intelligence level and comorbid clinical disorders, continue with the explanation of the social factors like the family structure studies, peer influences and rejection, and occupational employment or economic deprivation.

It is clear that the important issue would not be the influence of these facts due to its relationship to the antisocial conduct in people with the Attention-Deficit and Hyperactivity Disorder but, moreover, its continuity in the criminal path, so, would it be suitable to admit the criminal persistence in the following years or after early appearances? Would the Attention-Deficit and Hyperactivity Disorder, the external symptomatology or the comorbidity be the explanation?

Regarding the criminology aspects and its effects in the Attention-Deficit and Hyperactivity Disorder in the development of disruptive antisocial and criminal conducts, and in spite of the references that by the APA regarding risk factors, it points out that those are not enough cause nor will they act as the other individuals, from

${ }^{15}$ Further information in http://www.healthcentral.com/adhd/understanding-adhd-000030_2-145.html

${ }^{16}$ The National Institute for Health and Care Excellence. Reference in www.nice.org.uk. 
which I understand that these will not always intercede in the individuals with ADHD producing the same consequences and benefiting criminality. In this sense, the necessity of delimiting the risk factors that influence the pathology is based on the analysis of the probability that the subject could develop certain future antisocial behaviors, understanding that this connection would be the key for crime prevention programmes. Moreover, not only the risk factors could determine the evolution to the outsourcing of illicit conducts but those could be even differentiated according to the type and intensity of those features as well as being reduced by the protection elements (Aguilar Cárceles, 2013).

Instead of understanding the ADHD as a risk factor, we should focus on the symptomatology that could explain the link to crime and legal aspects, all of this from diverse predominant risk factors at biological level that would be explicit through the action of external aspects. In particular, we add the possibility of presenting determined risk factors in influencing certain stages of development opposite to others which does not include its necessary exclusion to understand that they could not influence but their important assessment depending on the probability of action.

However, before starts, we would like to indicate that criminal behavior would be the resulting effect from the interaction of great diversity of factors, but we can never consider them as strong enough factor. In this sense, following Farrington and Welsh (2007), risk factors refer the capacity of prediction of future offences.

After seeing the undeniable biological vulnerability in infants with ADHD the delimitation of the disorder would be unquestionable without taking into account the social aspects. According to them, we can affirm the following:

- The intelligence and criminality could lead to be interceded by features such as the language acquisition, non-verbal intelligence, academic results or school abandonment, which could predict the later unsuitable behaviors (Farrington, 2009). For example, it has been affirmed that a low Intelligence Quotient in so early ages as 3, could even lead to predict the risk of illicit conducts until twenty-seven years later (Stattin \& Klackenberg-Larson, 1993). Furthermore, we consider that the IQ of the infant with Attention-Deficit and Hyperactivity Disorder would be assessed separately from the level of school attendance and achievements, because although they are similar aspects, do not have to coincide, especially if there is truancy or school abandonment. This symptoms can even result in peer rejection (Kreager, 2004; Rebellón, 2006; Knetch, Snijders, Baerveldt, Steglich, \& Raub, 2010).

- The socioeconomic status (Boyle \& Lipman, 2002; Namdari, Nzari, \& Pournia, 2012) and unemployment, the unstable presence of work or unqualified jobs could be considered as indicators of illicit conducts (Fletcher, 2013). In this sense, the own family experience of the situation joined with the symptomatology of the infant, would indicate this path. We can see then, that not only the work situation of the parents but also the adult with Attention-Deficit and Hyperactivity Disorder will also link to these effects (for example, the high levels of unemployment in adults with Attention-Deficit and Hyperactivity Disorder).

- The low weight at birth could happen three times more often in infants with Attention-Deficit and Hyperactivity Disorder (Strang-Karlsson, Räikkönen, Pesonen, Kajantie, Paavonen, Lahti, Hovi, Heinonen, Järvenpää, Eriksson, \& Andersson, 2008), which could lead to late development of maturity, to the own characteristics of the infant and the action parents to them (for example, frequent cry), among other aspects. Nevertheless, authors as Getahun, Rhoads, Demissie, Lu, Quinn, Fassett, Wing and Jacobsen (2013: p. 53) inform that "the findings of this study suggest that IHCs (ischemic-hypoxic conditions), especially birth asphyxia, neonatal RDS (respiratory distress syndrome), and preeclampsia, are associated with ADHD in childhood even after accounting for gestational age and other potential risk factors. This association was strongest in preterm births. This suggests that events in pregnancy contribute to the etiology of this condition over and above the well-known familial/genetic influences". Otherwise, they say that "although previous studies indicate that perinatal factors are associated with altered neurodevelopment, data on the association between ischemic-hypoxic conditions and attentiondeficit/hyperactivity disorder in children are sparse”.

- The prenatal experience could help to explain later legal problems even in adulthood, being exactly the external symptoms of the Attention-Deficit and Hyperactivity Disorder which determined the path according to neurochemical explanations such as the lack of control and the reduction of the inhibitory impulse (Mick, Biederman, Faraone, Sayer, \& Kleinman, 2002). For example, smoker mother or alcohol intake during pregnancy would increase the probability of appearance of Attention-Deficit and Hyperactivity Disorder and even the later criminal path according to the described symptoms (Portnoy, Gao, Gelnn, Niv, Peskin, Rudo-Hutt, Schug, Yang, \& Raine, 2013). 
- It is discussed if a poor diet can influence in the behavior of the person with ADHD (Brenner, 1977; Wender \& Soltano, 1991; Fonagy, Target, Cottrell, Phillips, \& Kurtz, 2003), but what we are pretty sure is to admit that different from that point will be the fact of malnutrition that could result in similar symptoms of ADHD (Soutullo Esperón, 2008).

- The size of the family, the antisocial characteristics of the parents, abuse during childhood and styles of the parents to face problems and discipline would mark a very important part of the path of the infant, maybe because the can influence as first markers of criminality at early ages in the parent-child relationships (Welsh \& Farrington 2013). Even more, authors as Barbudo, Correas and Quintero affirm that personality structure of ADHD is not due to neurological deficit but childrearing and parenting avatars (Barbudo, Correas, \& Quintero, 2009). According to this last point, it can be admitted that: 1) the own symptomatology of the ADHD could have an effect on the parents and they way they have to interact with (McKee, Harvey, Edanforth, Ulaszek, \& Friedman, 2004) or in their parenting style (Smith \& Stern, 1997); 2) the number of brothers and sisters and, in particular, the presence of older examples to follow is considered a very important factor in the infants (Farrington, $1_{1992)^{17}}$; and 3) bigger risk of having abuse in childhood ${ }^{18}$, explained by the existence of abuse from the parents and linked to a poor embracing of the prosocial conducts and an increase of the aggressive tendencies by the infant. This last point could lead to increase the risk of repetition and imitation by the infant, it could be understood as an early trauma with the criminological consequences explained in the Intergenerational Transmission of Violence Theory (Morillas Fernández \& Luna Castillo, 2006).

The early appearance predicts its worse prognosis and less probability of desistence (Loeber \& Farrington, 2001), what joined to biological factors would facilitate a more chronic and severe evolution. In this point, we should emphasize the concept of resilience as an endogenous mechanism of individual protection that could limit the effects of this group of risk factors ${ }^{19}$. Joined to this last point, Bartol affirms that "buffering factors help children and adolescent to build resilience" (2006: p. 83) ${ }^{20}$, so it let them getting strategies to face possible adversities in the next future (Yates, Egeland, \& Sroufe, 2003).

Focusing on ADHD and its main symptoms, authors as Farrington informs that hyperactivity and impulsivity would be consider one of the most relevant individual and personality factors in the prediction of future delincuency (Farrington, 2009).

Although some certain features like impulsiveness would be some of the aspects related to the violent beha-

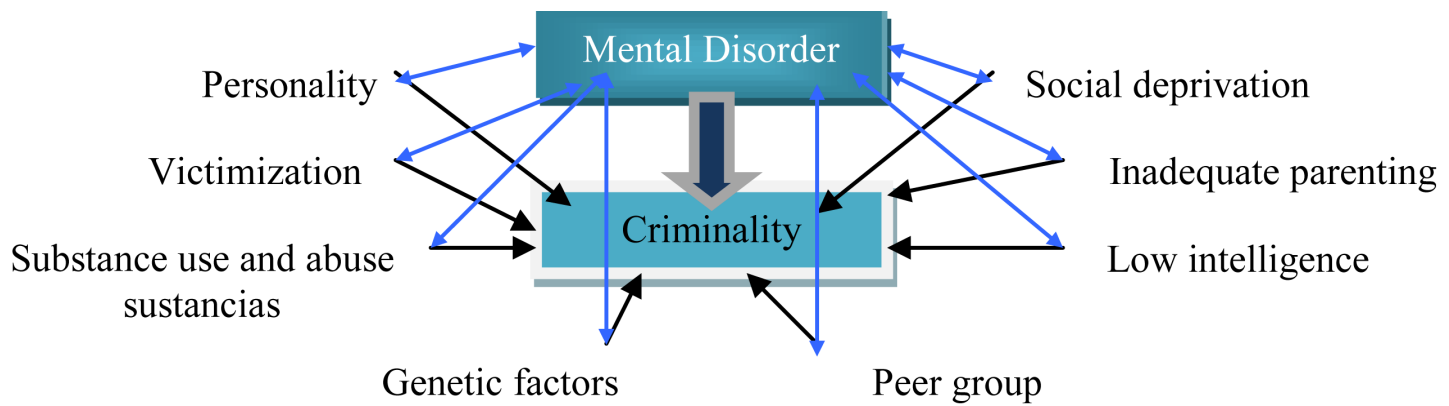

Figure 4. Link between a Mental Disorder and criminality (Thompson \& Darjee, 2009).

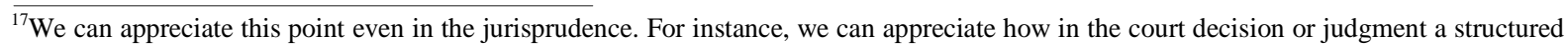
and non-structured familiar circle can influence in the adolescent with ADHD, however, in both cases ADHD appears associated to criminality. These are the cases of the Sentence Audiencia Provincial de Valladolid 13/2009, de 22 de enero [JUR 2009\286118], where the minor lives in a structural family with adequate parenting styles and the Sentencia de la Audiencia Provincial de Cantabria 229/2011, de 19 de mayo [JUR 2012 1374644], where the lack of assistance by the parents has increased the risk of antisocial behaviors.

${ }^{18}$ The American Psychiatric Association refers the relevance of history of abuse and neglect in minors with ADHD and its impact in later years. This situation can be understood as a risk factor for the person who has a ADHD Diagnosis, or even for other Disorders (Post-Traumatic Stress Disorder, Bordeline), anyway these situations based on traumatic events in first years can facilitate the criminal trajectory (APA 2013: p. 62). Research studies have shown how it can lead to repeat this behavior of abuse in adulthood (intergenerational transmission of violence) (Yun, Ball, \& Lin, 2011).

${ }^{19}$ Even we can talk about this concept in victimization, helping people to recoup from a traumatic event (crime or not) (Morillas Fernández, Patró Hernández, \& Aguilar Cárceles, 2014).

${ }^{20}$ In the same sense, authors as F. Lösel (2013) indicates that estabilidad emosiocnal, comprosimos con las responsabilidadaes socials u competencias a nivel cognitive y temperament fácil factores potenciadores. Lecture on "What works in correctional treatment and offender rehabilitation?”, by Professor Friedrich Lösel, MSt Programmes in Applied Criminology (Penology Programme \& Police Executive Programme), held in the Little Hall, University of Cambridge, $4^{\text {th }}$ July 2013.
} 
vior, we could admit that the external symptomatology of the illness itself would predict fights or adolescent violence but it would be not directly related to the ADHD and criminality but associated with other psychopathologies (comorbidity). Thompson and Darjee draw the following Figure 4 to explain the general relation to explain the link between a Mental Disorder and criminality (where we can include ADHD):

According to this figure, we hardly understand that the link between a Mental Disorder and criminality should be bidirectional and no unidirectional. In this way, it is possible to develop psychiatric symptoms even disorders-from antisocial behavior and criminality, moreover once the person has to serve the Sentence (e.g. depersonalisation).

From this we have the necessity of pointing out that only a minority of individuals with Attention-Deficit and Hyperactivity Disorder will evolve to crime in particular those who show characteristics such as impudence, search of sensations or presence of Oppositional Defiant Disorder, Conduct Disorders, Antisocial Personality Disorder or Substance-Related and Addictive Disorder, among others. We can see that these are the aspects which would define personality and frequently, they would be present in criminals without a diagnosed pathology, concluding that in most cases criminal behavior correlate positively with external conduct problems and negatively with the internal ones (Stemmler \& Lösel, 2012).

We can see that the subject with Attention-Deficit and Hyperactivity Disorder will have the possibility to develop antisocial behaviors in a very small proportion compared with when this diagnosis is comorbid to other pathologies being external symptomatology the common indicator, in particular, impulsiveness.

In this sense, it is not strange that impulsiveness is one of the most related features with criminality when we know that this behavior will be positively related to the external conduct problems and negatively with the internal. But in the case of the Attention-Deficit and Hyperactivity Disorder the same will be characterised by being more reactive than proactive, although not in all subjects nor in all stages. According to this and due to the symptomatology influence of other illnesses, the criminal behaviors explained with this feature will have to be more proactive in the case of Oppositional Defiant Disorder, Conduct Disorder or Antisocial Personality Disorder, from which I understand that the qualification and characterization of impulsiveness could vary depending on different consequences. This is the reason for the evolution of the Attention-Deficit and Hyperactivity Disorder to the mentioned illnesses and the interceded explanation of criminality in most of the assumptions.

The own process of brain maturity would increase the abilities to inhibit the impulses through the years, to be more capable of showing a social behavior and guide in this sense the aggressive and violent actions. From the point of view of normalization of development, the age will guide this kind of responses, we could say that there is a decrease in the appearance of physical aggressive behavior in most of the children when they learn how to use alternatives to these, also noticing that in later stages (adolescence-adulthood) this kind of aggressiveness linked to violent crimes decreases with age.

The early beginning of hyperactive-impulsive symptomatology goes on with a higher risk of comorbidity that would benefit the development of malfunction behaviors, but when we have to set out rates of continuity of criminality in adulthood is enough to notice that the presence or absence of a diagnosed illness would not be determinant in the path regarding the setting of the type, the analysis of the persistence is established in general terms about the number of criminals because, in the end, the result against the Law is not different from the action but the responsibility of the person. With this I want to say that the independence of the existence of a mental pathology, the conduct will create the result, depending exclusively the imposed measure but not conditioning that it is considered or not as crime, but the criminal responsibility.

\subsection{Research Studies about Starting and Persistence of ADHD}

From two of the more relevant studies regarding the analysis of the criminal path, The Cambridge Study in Delinquent Development ${ }^{21}$ and The Pittsburgh Youth Study ${ }^{22}$, we can admit that the peak age in the criminal path would be between 17 and 18, the age of contact of chronic delinquents with the Legal System is less, even when they are 7, this way, who commit crime when they are young show more crimes when they are older and their

\footnotetext{
${ }^{21}$ The Cambridge Study in Delinquent Development based its analysis in male gender because of the high level of crimes-mainly violencethat are committed by this group in comparison with female gender.

${ }^{22}$ Information given by the Office of Justice Program (1999). Highlights of findings from the Pittsburgh Youth Study, Office of Juvenil Justice and Delinquency Prevention, US Department of Justice. https://www.ncjrs.gov/pdffiles1/fs9995.pdf.
} 
criminal path is longer. It would then be included that the early beginning will mark later severity so there will be a higher probability of becoming chronic young delinquents. The fact that the chronicity is higher does not mean that the committed crimes are more violent, on the contrary, we can admit that the violent delinquency would be increased later and that there would be more cases of this kind.

We agree on admitting the possible menace of the individuals who start their criminal path between 7 and 12, being curious that exactly this range of age is extended for the diagnosis of Attention-Deficit and Hyperactivity Disorder and it is from this age when it is more probable to notice actions against the rules in the convergence with other disorders. For this, we should indicate the following: a) there would be a smaller percentage of infants that could develop a chronic conduct compared with the ones who cease this behavior, so the worst result would not be the most frequent; b) it is admitted that the first illicit conducts in adulthood (late adolescence) will constitute nearly the half of the total of the adult delinquent population; and c) for most of the earnest criminals the delinquency would be preceded by a list of problems of non-criminal conduct.

The findings are strict affirming that the link between the beginning and the persistence of the criminal path, this is, the beginning at an early age would be indicator not only for the continuity of delinquency but also for the great number of crimes (even with 5 years old) standing out that the levels of impulsiveness due to its special relation with this appearance. Moreover, in its relation with the Attention-Deficit and Hyperactivity Disorder an early set of the delinquency would increase the probability of committing chronic and severe crimes in the future doubling and even tripling the probability opposite the subjects who start later; moreover, there is important evidence about that the Attention-Deficit and Hyperactivity Disorder would be related to the early beginning of conduct problems and would influence in the risk after this kind of actions. But if we admit that the Attention-Deficit and Hyperactivity Disorder with no associated conduct problems will not lead to these results; that is, we suggest the fact that it would be very difficult that the disorder itself could explain the development of the mentioned conducts if it is not interceded by comorbid disorders or other features. In spite of that, the existence of a risk is an obvious fact due to impulsiveness, placing the problem in figuring out that the impulsive symptomatology before 7 is a consequence of an ADHD, ODD and CD.

Adding the previous point to the importance of biological predispositions, we could admit that the existence of an intergenerational continuity explained by the exposure to several factors from whom suffer from Attention-Deficit and Hyperactivity Disorder and is linked to criminality, being the experiences in childhood very important to delimit this path. However, in general we could say that not all criminals will show rates of criminality at early ages, being delinquency reasonably predictable in an early way only in some infants. Likewise, antisocial behavior would be a type of delinquency among young people predicting delinquency in adulthood (antisocial potential) (Redondo Illescas \& Garrido Genovés, 2013).

This way, in its application to the ADHD, it remarks that the disorder itself or its external symptomatology focused on impulsiveness, would be one of the most important risk factors in the prediction of later delinquency, being very bound not only to comorbidity but also to other group of circumstances such as bad academic records, poverty in the family, large family, malfunction of the family environment or bad parenting style, among others. Regarding this and being impulsiveness the feature linked to will or capacity of self-determination in the conduct of the Attention-Deficit and Hyperactivity Disorder, we would admit its modeling as a possibility of change and control, probability of change that would be linked to self-management of the behavior (for example, research on rewards).

To sum up with this point, we consider very relevant the statement made by Farrington when he says that "delinquency is part of a bigger antisocial behavior syndrome that begins in childhood and persists into adulthood. It seems as continuous over the time, the antisocial behavior in childhood tend to be antisocial in adolescence and later in adulthood” (Farrington, 2009: p. 1908).

\section{Comorbidity as the Essence to Explain Criminal Careers in Next Years}

\subsection{How Does DSM New Structure Affect to Explain the Continuity of ADHD and Its Link to Comorbidity?}

ADHD as the most frequent nosological entity in childhood ${ }^{23}$ appears with a high level of co-occurring with

\footnotetext{
${ }^{23}$ ADHD joined to Anxiety Disorders are the most prevalent psychiatric conditions during childhood and adolescence (Yoo, Choo, SKim, Kim, Shin, \& Hong, 2005).
} 
other pathologies ${ }^{24}$, the most relevant are the ones which are commonly linked to the criminal path: Oppositional Defiant Disorder, Conduct Disorder, Conduct Disorder linked to Substance Abuse, and Personality Disorders, mainly Antisocial and Borderline ${ }^{25}$. However, "only a minimum percentage of people with ADHD diagnosis in childhood will develop conduct problems” (Goldstein, 2002: p. 25), concluding ADHD as a strong predictor in the development of other disorders during adolescence and adulthood (Yoshimasu, Bareresi, Colligan, Voigt, Killian, Weaver, \& Katusic, 2012).

The comorbidity is presented as a sign of severity of symptoms and chronicity, noticing that this co-occurrence is high and in most of the cases of adults with the combined subtype. The Attention-Deficit and Hyperactivity Disorder is then organised as a strong indicator of a wide range of psychopathologies in adolescence and adulthood, internal or external, but not only in the diagnosis of the disorder in childhood would be a strong indicator or risk factor but depending on the age of the appearance of symptoms and the subtype of ADHD so would be the possible consequences. Always talking about probability, there is no doubt that an earlier beginning will lead to worse consequences, moreover, not the beginning of the illness but the beginning of the external symptomatology of lack of attention, these external appearances would be noticed in a minor range, but when they do it, they will have more probabilities of association to these pathologies linked to the criminal path, this is exactly due to its high symptomatology confluence. An example of this would be the impulsiveness in clinical disturbances such as Oppositional Defiant Disorder, Conduct Disorder or Substance-Related and Addictive Disord$\mathrm{er}^{26}$

There are a lot of changes made by the APA with the DSM-5 at content level and about structure (for example, the elimination of the types of schizophrenia, the possibility of co-occurrence Autism Spectrum Disorder with Attention-Deficit and Hyperactivity Disorder, separation of the Oppositional Defiant Disorders from the Anxiety Disorders, and inclusion of new illnesses such as Excoriation Disorder, Compulsive hoarding, etc.) we focus the main question in the link with the Attention-Deficit and Hyperactivity Disorder and other mental illnesses that

\footnotetext{
${ }^{24}$ We focus the attention in those that have a major link to criminality, but we can highlight other disorders that can even result in a great impact in the person who suffer from ADHD. For instance, specific learning disorders, autism spectrum disorders or motor disorder. According mainly to the first group of disorders we must emphasize the necessary attention to educational diversity and the deployment of adequate measures to this collective. Even by the Congress of Deputies (In Spain, The Cortes Generales comprises two Houses: the Congress of Deputies and the Senate), encourages local and regional administrations to take part in this "social problem". The educational field is one of the biggest worries by parents and one of the best ways to implement early intervention. Concretely, proof of that is the new tool elaborate by Russell A. Barkly, first online school to contribute not only with minor diagnosis with ADHD but with their parents and caregivers. Noticia en prensa del 1 de febrero de 2014.

http://www.abc.es/familia-padres-hijos/20140201/abci-escuela-online-201401241242.html. Regarding infants with Attention-Deficit and Hyperactivity Disorder, we should underline that the passing condition of infants comes from Article 19 of the Criminal Code, coming from the Spanish Law on the Responsibilities of the Infant in which the presence of the illness is not mentioned. In spite of that, we consider very important the legal recognition regarding this group with the new Law on Education (LOMCE) where the Attention-Deficit and Hyperactivity Disorder is mentioned (this was foreseen by the Spanish Legislative Organs since 2012, when the President was told to introduced new measures and strategies to detect it and leaving it under the frame of a General Plan for the Quality of the Health System). I understand that the importance comes from the necessity of knowing the requirements by the infants during early childhood when the consequences of no intervention from the beginning will lead probably to poor academic records and school abandonment. However, this measure on the regulations keeps on prioritizing aspects of regional criteria instead of real necessities. There is no doubt that there are currently a lot of initiatives in the school and health fields. One of the most important is the creation of the first online school for parents and professionals that live with the Attention-Deficit and Hyperactivity Disorder, in 2014. All of this has been carried out thanks to Mr. Russel E. Barkley, one of the most important researchers on the pathology worldwide. I consider the justification based on the following: 1) The Attention-Deficit and Hyperactivity Disorder is considered one of the easiest disorders regarding diagnose. Form the point of view of the child psychopathology, the treatment with these infants can considerably evolve towards normalization of the behaviors that, at explicit and implicit level, characterize the subject. 2) The earlier detection and treatment would be the key to the future adaptation of the infant, reducing its symptomatology that, from the early stages, will show the difficulty to acquire basic abilities, relationships, or school abandonment. 3) The school in the first moments, parents and guardians, would be defined as agents of detection of the disorder which could not be seen when the symptomatology is mainly related to attention, at the same time they can be considered absorbed children with poor interpersonal abilities, impulsive or hyperactive that could be defined as badly brought up with independence of the current overdiagnosis when the symptoms appear. Further information: Federación Española de Asociaciones de Ayuda al Déficit de Atención e Hiperactividad (FEAADAH),

http://www.feaadah.org/es/difusion/winarcdoc.php?id=360. In this context, we have to highlight the relevant contributions made by its President D. Fulgencio Madrid Conesa. For instcane: Madrid Conesa, F. (2009). El impacto social del Trastorno por Déficit de Atención e Hiperactividad. Universidad de Salamanca; Madrid Conesa, F. (2013). La situación del TDAH en España. Madrid: Adelphi Targis; and Madrid Conesa, F. (2014). TDAH y delitos. En el impacto social del TDAH. Madrid: Adelphi Targis. In this sense, a research study made by Morillas Fernández and Aguilar Cárceles (2014) shows how minors with ADHD diagnosis in fulfillment of legal measures are characterized for coming from dysfunctional families, broken homes, conflicts with parents and earlier substance consumption.

${ }^{25}$ In general, as Nottelmann and Jensen (1995: pp. 109-155) affirm, "more than 30\% of children with ADHD have another disoder”, rate even higher in adults, almost 60\% (Spencer, Biederman, Wilens, \& Faraone, 1998).

${ }^{26}$ We have to know that impulsivity is the most representative second syptom after clinical significance, what is not strange to explain comorbidity between several diagnoses (APA, 2013).
} 
are currently placed under the general name of Disruptive, Impulsive-Control and Conduct Disorders, more concretely the Oppositional Defiant Disorder and Conduct Disorder, because they are the illnesses which will indicate the link to criminality.

In this new chapter by the APA, the selection of the group of diagnosis categories placed now under the Disruptive, Impulsive-Control and Conduct Disorders, is justified by the fact that the lack of self-regulation at emotional and behavioral level links all of them. There are two big groups: the problems related to self-control (appearance of anger and aggressiveness) and the absence of impulse control but related to certain behaviors set to an external objective, where the purpose is finish with internal tensions. The Antisocial Personality Disorder would be placed in this group which is marked in the Chapter of Personality Disorders.

A clear example of this explanation can be found in the following Figure 5 in which we can see the changes in the structuring of DSM-5.

We understand that the separation of these psychopathologies is justified according to the following points:

- The link of the Attention-Deficit and Hyperactivity Disorder with other early diagnosed illnesses.

- The comprehension of this Disorder as a Neurodevelopmental one with very different particularities from the Oppositional Defiant Disorder and Conduct Disorder.

- The consequences that the diagnosis could mean for the individual with independence of clinic comorbidity.

\subsection{Would It Be Possible to Explain Criminal Career Exclusively with a Single Diagnosis of ADHD?}

\subsubsection{ADHD and Oppositional-Defiant and Conduct Disorder}

The scientific literature makes also evident the importance of the link of the Attention-Deficit and Hyperactivity Disorder to disturbances characterized by a bigger presence of an external symptomatology. These disturbances are defined by a high level of impulsiveness, irritability, low tolerance to frustration, aggressiveness or the necessity of immediate gratification (absence of empathy) (Slutske, Cronk, \& Nabors-Oberg, 2003), among other aspects, all of them are present in the high prevalence not only in the Oppositional Defiant Disorder and Conduct Disorder already described but also in which is related to the consumption of substances and modified characteristics of personality. In spite of that, could even certain disorders characterized by a superiority of internal symptomatology predict such consequences?

According to Fletcher and Wolfe, the own ADHD symptomatology would substantially increase the probability of jutting out in criminal activities (Fletcher \& Wolfe, 2009), furthermore, hyperactivity and impulsivity in combination with a Conduct Disorder will predict this trajectory (Babinski, Hartsough, \& Lambert, 1999). Its chronicity will predict the severest consequences so, although we notice that the biggest relationship occurs between ODD and CD (Figure 6). In this sense, Lahey, Mc Burnett and Loeber indicate that "although is clear

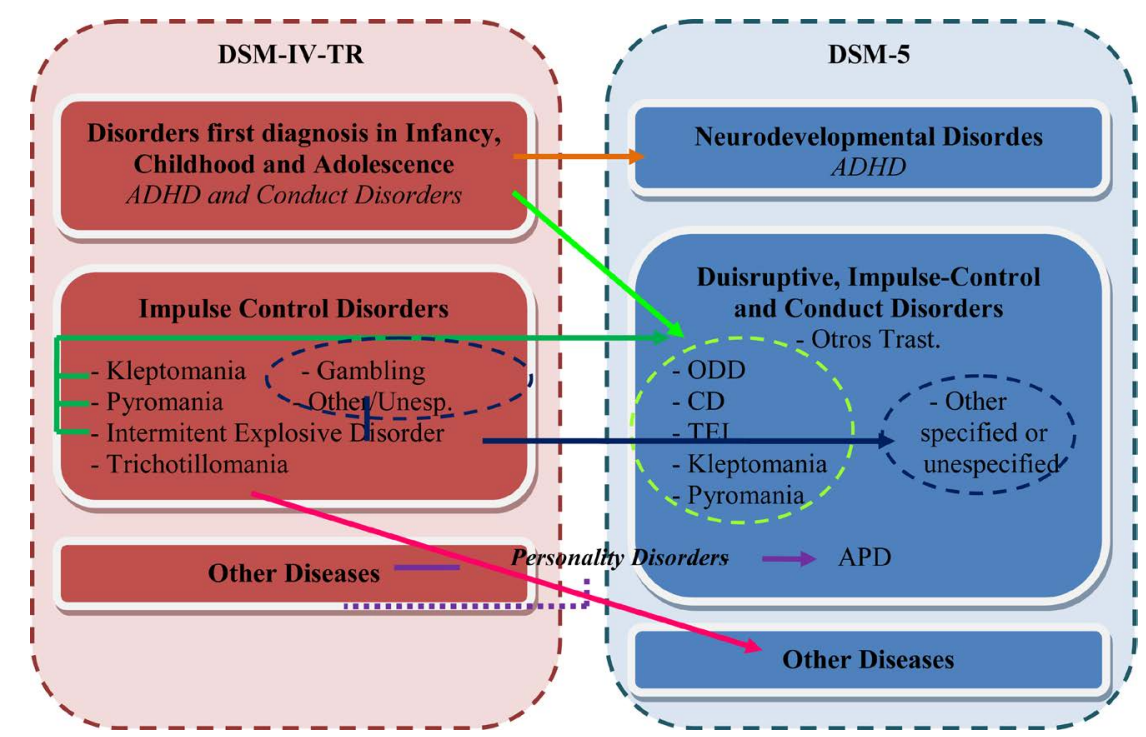

Figure 5. DSM new structure focusing on ADHD (Aguilar Cárceles, 2014: p. 264). 


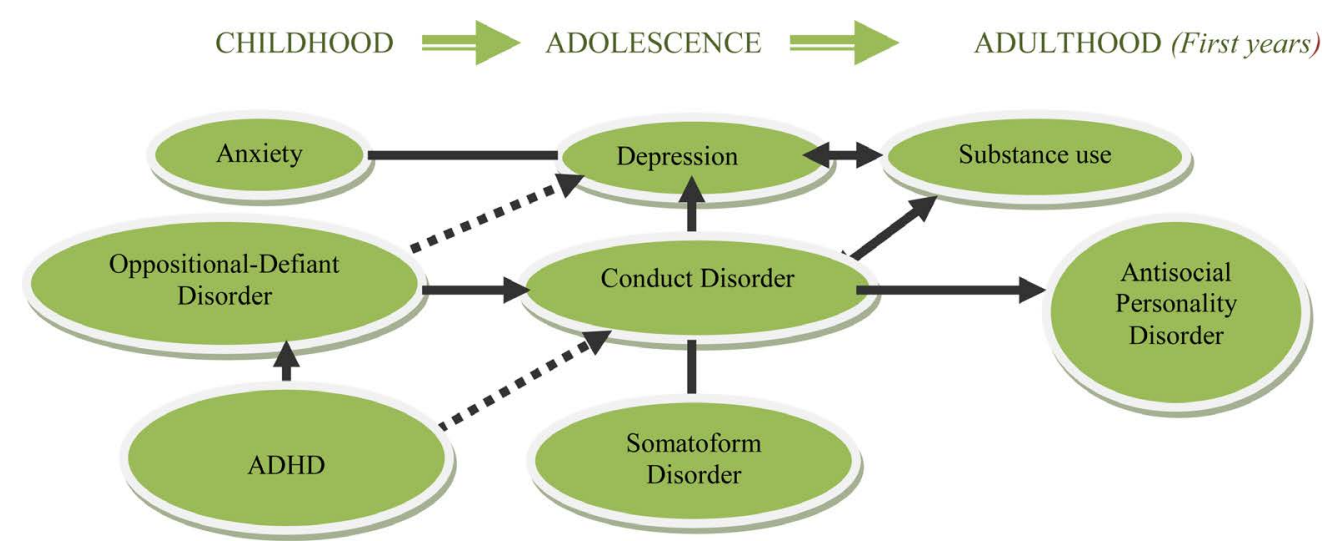

Figure 6. Link between ADHD-ODD-CD (Loeber, Burke, Lahey, Winters, \& Zera, 2000).

that minors with ADHD diagnosis in first years as a major risk of presenting ODD than those without diagnosis, it could be resulted by the higher degree of comorbidity between this last and the CD” (2000: p. 442). The authors continue indicating that persistence and severity of ODD-CD would be higher when the ADHD is diagnosed earlier. Contrary, hyperactive children without conduct problems do not have a risk to develop later criminality (Mannuzza, Klein, Bessler, Malloy, \& LaPadula, 1998).

Focusing on the Disruptive Behavior Disorders, where Oppositional Defiant Disorder and Conduct Disorder would be placed, we make the question that if the Attention-Deficit and Hyperactivity Disorder would be simply a structural change of these disorders. In previous editions of the DSM it was placed under a common Title, moreover, until what extent could its presence lead to crime? Would the existence of an Oppositional Defiant Disorder and/or a Conduct Disorder be a requirement so that an individual with Attention-Deficit and Hyperactivity Disorder becomes a criminal? Or would it be the same if the Attention-Deficit and Hyperactivity Disorder is the only illness?

The link between ADHD, the Oppositional Defiant Disorder (ODD) and the Conduct Disorder (CD), is an evidence, what bring us to ask the question about the necessity of laying out if they are really disorders in which there could only be an structural change or if differential diagnosis and content or definitions very different from others could be established concluding that they are not ranks or representations of the same illness. In spite of the existence of common characteristics that could influence on them in the same direction, they are not changes of the same clinical spectrum but independent units with a high symptomatology and diagnosis comorbidity, where the co-occurrence would be indicated by the appearance of a symptomatology hyperactivity-impulsiveness (Newcorn, Halperin, \& Miller, 2010). The impulsiveness would be the one exactly shared with the Attention-Deficit and Hyperactivity Disorder, the Oppositional Defiant Disorder and the Conduct Disorder, being an essential indicator of the comorbidity.

According to the well-known tri-morbidity ADHD-ODD-CD (Connor, Ford, Chapman, \& Banga, 2012), we can conclude the following aspects:

- The comorbidity among them is one of the changes of the DSM-5. In previous editions the existence of the criteria for the Oppositional Defiant Disorder and Conduct Disorder was indicated but since 2013 it influences the probability of co-occurrence. Moreover, it indicates that in the general population the co-occurrence Attention-Deficit and Hyperactivity Disorder and Oppositional Defiant Disorder is frequent mainly in half of the children with combined subtype and in a fourth of the inattentive subtype. From this probability of association, as analyzed in the text, it would be justified the fact to admit inside the combined subtype, the presence of symptoms of lack of attention could act in some of these senses: a) the bigger symptomatology disturbances, in quantity and description, will create a greater number of malfunctions in the individual which does not mean that these disturbances are linked to criminality because this last relation will be predominant in the presence of severe external symptomatology; b) the possibility of comorbidity with pathologies with a bigger characterisation of internal symptomatology in the presence of strong external components could increase the presence of certain illnesses (for example, the mood swing in the Borderline Disorder); and c) there is no doubt that the absence of a direct link lack of attention-criminality like the one which should describe impulsiveness, specially at legal level when the Law excludes the deficit in the capacity of attention as cause not subject to prosecution. 
Different from the previous would be the predominance of the inattentive subtype in the Attention-Deficit and Hyperactivity Disorder where it is clear that the external symptomatology would be apart from the diagnosis.

- It would be frequent that a person with Attention-Deficit and Hyperactivity Disorder would be diagnosed with Oppositional Defiant Disorder and Conduct Disorder but this possibility would diminish in adolescence and adulthood-as we notice in its prevalence-. It is a logical aspect because it places the diagnosis before this stage. Everything is showed by the differences among them, while the Oppositional Defiant Disorder would be define as a pattern of disobedience, defiance, offence, irritability, rage, snub to other people and social values, arguments (Tremblay, 2013), in the Conduct Disorder the severity would be stronger based on a pattern of aggressive behavior to other people and cruelty to animals, destruction of property, theft and fraud, among others.

- It is odd the fact that in relation to age, although it is not appreciated in any of the illnesses, in the case of Oppositional Defiant Disorder a group of characteristics that start before 5 is indicated. We do the same for the Conduct Disorder depending on if the appearance of the first symptoms is before or after 10. It would be curious to notice the overlapping with the age for the diagnosis of the Attention-Deficit and Hyperactivity Disorder, when the symptoms would be more difficult to find before 4 - 5 but could be observed. It would be maybe suitable to establish the basis according to characteristics such as impulsiveness that could warn about co-occurrence in the first stages.

- The inclusion by the APA is important when indicating the possible notice of a group of instructions about the existence or not of prosocial limited emotions, where we differentiate: a) absence of regrets; b) absence of empathy; c) worry about the conduct and its results, d) poor affection. I personally understand that this is a very correct inclusion because it allows us to notice about motivation or intrinsic characteristics that could take the subject to a certain conduct, adding then the importance of the intrinsic factors, in particular the ones related to the prosocial conduct in this illness (Conduct Disorder). Thus, empathy and prosocial behavior would represent an important nuclear role regarding the perpetuity of the behavior, intentionality or deliberation, and regarding the possible reintegration—overall in offenders with ADHD diagnose ${ }^{27}$.

- This is why we could say that the early beginning of the Oppositional Defiant Disorder and Conduct Disorder would be an indicator of severity (APA, 2013), leaving the comorbidity mainly linked to aggressiveness and Antisocial Personality Disorder in later ages (Loeber, Burke, \& Lahey, 2002). In addition, the Oppositional Defiant Disorder is considered prodrome of the Conduct Disorder (Whittinger, Langley, Fowlerm, Thomas, \& Thapar, 2007), which would benefit the appearance of psychopathologies as the indicated. In this sense, the worst results would come from the diagnosis of the Oppositional Defiant Disorder previous to the Conduct Disorder, and it emphasizes when there is an early diagnosis of Attention-Deficit and Hyperactivity Disorder. According to this tri-morbidity, it would be exactly this common presence the one that could predict the development of later and more severe disorders but, as I mentioned, supported by impulsiveness.

- The early symptoms of ADHD could act as a precursor of antisocial actions and later crimes due to the higher levels of impulsiveness when comorbidity exists with the mentioned illnesses. Besides, regarding to this point, Álvarez and Ollendick (2003) affirm that "recent investigations support that will be impulsivity but no hyperactivity what predict later antisocial behaviors" (Álvarez \& Ollendick, 2003: pp. 107-108). Impulsiveness is established as a nuclear factor in the prediction of bad behavior in the future. The risk associated with Attention-Deficit and Hyperactivity Disorder is exclusively in cases of combined type and/or with an important load of external symptomatology, the development of the criminal career will depend of the subtype (Murphy, Barkley, \& Bush, 2002).

Obviously, comorbidity is the one which supports most of the consequences but precisely because the infant already showed nuclear features of the disorders since early childhood, namely, impulsiveness.

\subsubsection{ADHD and Substance-Related and Addictive Disorders}

Regarding its link to the Substance-Related and Addictive Disorder, the poor neuroadaptation derived from the consumption or related symptoms could reach a malfunction rank understood as extreme severity, which could also explain the link of this behavior and the Legal System with the development of antisocial conducts. According to this, the APA points out that "children with Attention-Deficit and Hyperactivity Disorder have a significant higher probability than their schoolmates without it of developing a Conduct Disorder during adoles-

\footnotetext{
${ }^{27}$ As example of research study that assesses empahty in a penitentiary sample and the link of this variable with the antisocial act already done, we can consult Aguilar Cárceles \& Godoy Fernández (2013), or even in Aguilar Cárceles, Godoy Fernández, Sánchez-Meca, Martínez-Hernández \& Laosa Jiménez (2011).
} 
cence and Antisocial Personality during adulthood increasing the risk of use of drugs and imprisonment”. They also add the largest probability of being damaged, car accidents or break the traffic rules. Nevertheless, we should be quiet on this because the DSM-5 indicates that the appearance of Attention-Deficit and Hyperactivity Disorder with a Substance-Related and Addictive Disorder is larger in these individuals than in the normal population, this link will only occur in a minority of the cases.

Inside this group, impulsiveness is again the nuclear feature, where the ADHD in this context would respond to the existence of a premorbid vulnerability in individuals with high levels of impulsiveness. For instance, in people which have problems with alcoholism, Edwards and Kendler (2012) affirm that externalizing problems in adolescence could get to increase further problems in adulthood, what they also link to ODD and CD (Edwards \& Kendler, 2012). Furthermore, Lee, Humpreys, Flory, Liu and Glas affirm that the link between ADHD and Substance Use could come influenced by the presence of ODD or CD (Lee, Humpreys, Flory, Lui, \& Glas, 2011).

Moreover, regarding the link ADHD and Substance-Related and Addictive Disorder, it should be underlined that people with this diagnosis begin the consumption before and develop to chronicity quicker (and recurrent) (Verdejo, Lawerence, \& Clarck, 2008), being the consumption the most frequent conduct. In the same way, the frequency or habit is more repeated and could lead to be increased until five times if there is a Conduct Disorder, however, it would depend on the type of drug (Milberger, Biederman, Faraone, Chen, \& Jones, 1997).

The percentage of Abuse and Dependence found in adolescents with diagnosis of Attention-Deficit and Hyperactivity Disorder is larger than in the general population, being those conducts when the pathology of early beginning exists and noticing more frequency (Sullivan \& Levin, 2001). Regard to that, most of the antisocial activities are related to possession, distribution, use and selling of illegal drugs (Barkley, 2006).

On the other hand, and coming back to genetic risk factors, the genetic risk associated with the appearance of antisocial behaviors in adolescence is linked to the genetic risk in problems related to Addictions and Dependence, especially if we add the effect of the compulsive feature of the ADHD (Everitt, Belin, Economiduo, Pelloux, Dalley, \& Robbins, 2008) and its biological characteristics for the development of these conducts. That would be understood under the conclusion of similar symptomatology as the case of lack of inhibition or malfunctions given after long time consumption (Slutske, Cronk, \& Nabors-Oberg, 2003).

Definitely, impulsiveness would be the key to understand addictive phenomena being linked to them as an underlying indicator that would make easier the criminal conduct which would be aggravating for the consumption and intermediary to other risk factors or vulnerability to Addiction (Perry \& Carroll, 2008). Moreover, as we saw before, the external symptoms in adolescence are a key factor in justifying the problematic path in adulthood exactly due to the support at genetic level, that is, only the subtype hyperactive/impulsive would be significantly matched with the genetic level when other factor related to the Conduct Disorder are under control because the lack of attention would not be related to this kind of conducts, opposite to impulsiveness interceded by one of these pathologies.

To sum up, although comorbidity increment the risk of developing a Substance Use and Addictive Disorder in adults with diagnosis of ADHD, the mere presence of the diagnosis of ADHD is a risk factor for the Substance Use and Addictive Disorder (Biederman et al., 1995). In any case, this development will depend on the severity of the illness and especially, on the Conduct Disorder in adolescents. Again, all of this is justified attending to the feature of impulsiveness.

\subsubsection{ADHD and Personality Disorders}

In its relation to the Personality Disorder (PD), defined by a continuous pattern, with inflexible, not adaptable and chronic behavior which causes malfunction and incapacity to the individual who suffers from it, and which starts in early adulthood or late adolescence (APA, 2013), we could affirm that the appearance of the ADHD would depend on the interaction between the predominant personality characteristics so that the different appearances will also determine the different subtypes of the ADHD (Martel \& Nigg, 2006).

The impulsive symptomatology is especially important in the current version of the DSM because it mentions that the characterization of the functional pattern of the personality will have to be established in two of the following areas: 1) the cognoscitive one; 2) the affective one; 3) the interpersonal activity and 4) the control of the impulses. It is from this last category when the disorder will be associated with the configuration of temperamental specific features and the higher risk of suffering from Attention-Deficit and Hyperactivity Disorder later, mainly the Cluster B, in a larger proportion (Philipsen, 2006). 
The strongest impact of the Attention-Deficit and Hyperactivity Disorder on the Personality Disorders would be translated into a possible link with the Antisocial Personality Disorder and the Borderline Disorder, in particular regarding a convergent symptomatology or derived from the disorder (e.g. CD), especially the external type.

According to the APA (2013), the Antisocial Personality Disorder would be concretely characterized by the presence of recurrent interpersonal problems, low tolerance to frustration, incapacity to delay the reward, or the necessity of searching for new sensations, new challenges and risks. Everything would be related to the impulsive symptomatology when theres is a minimum or total absence of planification of the actions, pattern of disdain for other people, irritability or carelessness which could be reflected on car accidents (number and severity), among other aspects. Moreover, we should indicate the following in relation to the Antisocial Personality Disorder (APD): a) its frequency is common in the prison environment (until 70\%)_although not always the present an APD; b) it is linked especially to the male gender - there is no mention of figures among women in the DSM; c) high intergenerational continuity; d) remarkable alleviation of symptoms from 40, not only regarding the behavior related to crime but also the presence of comorbid disorders (for example, the Substance-Related and Addictive Disorder); e) the APA indicates that the probabilities to develop an Antisocial Personality Disorder in adulthood increase if the individual has a Conduct Disorder before 10 and an associated Attention-Deficit and Hyperactivity Disorder; f) the possible existence of maltreatment or abandonment in childhood, the parents' unstable or changeable behavior, or the unaware discipline by them, would increase the possibilities that the Conduct Disorder would evolve to an Antisocial Personality Disorder-again, the early diagnosis would be one of the most evident indicators of the chronicity and the co-occurrence; g) in general, the comorbidity among the Personality Disorders is common, independent from the belonging group, less with the Group B, inside which, the individual with Narcissistic Personality Disorder will be characterized, among other, by being less sincere and empathic, superficial, but there will be a lack of aggressiveness and impulsiveness that the Antisocial Personality Disorder would have. The individual with Histrionic Personality Disorder is impulsive, manipulative and reckless, with necessity of sensations, used to show emotions in much more exaggerated way and do not participate in antisocial conducts. The manipulation is also used by the individual with Borderline diagnosis but the aims would be very different from the Antisocial Personality Disorder which is emotionally less unstable.

In its link to the Attention-Deficit and Hyperactivity Disorder, the first difference would answer a chronological criteria regarding configuration or diagnosis of the illness, no later than 12 for the former and not before 18 for the later, being a condition in this one the presence of symptoms of the Conduct Disorder before 15 . This way, the APA says that "the diagnosis of the Antisocial Personality Disorder is not given in individuals younger than 18 and is only established if there are some symptoms before 15" and adds "in people older than 18 the diagnosis of Conduct Disorder is given only if the criteria for the Antisocial Personality Disorder are not met” (2013: p. 659). The disturbances in the basic cognitive processes, the higher levels of impulsiveness, the poor ability to act, the incapacity of planning, the undervaluing of the consequences, being a victim during childhood, chronic consumption, would be some of the characteristics of the Antisocial Personality Disorder and Attention-Deficit and Hyperactivity Disorder, all of this, due to its particularities would be in favour of the appearance of other disorders, like the one related to substance abuse. According to this, we can see the triple relation regarding persistence and severity where the chronic consumption is a disorder joining a Personality Disorder and the Attention-Deficit and Hyperactivity Disorder, that would predict the persistence of later antisocial conducts.

Regarding the Borderline Personality Disorder, the APA (2013) characterized this Disorder by its affective instability, reactions, irritability, aggressiveness, intolerance to abandonment or solitude, poor tolerance to frustration or boredom and high possibility of conducts of auto-victimisation (for example, self-harm or suicide), we should distinguish also the following aspects: a) not only the possibility of a process of victimisation, but also doing impulsive actions that would lead to a poor tolerance to frustration and boredom, being common the necessity to bet and spend money; b) its appearance is five times more probable when there are first-grade relatives, there is also a higher family risk than in normal population regarding the appearance of the SubstanceRelated and Addictive Disorder, Antisocial Personality Disorder, Depression and Bipolar Disorder; c) the physical and sexual abuse in childhood, negligences, familiar conflicts, early loss of parents are typical indicators of an individual with Borderline Personality Disorder; d) in the new edition of the DSM an important increase of the estimated prevalence from $1.6 \%$ to $5.9 \%$ is appreciated; e) its presence is higher in women (1:4); f) the path of the Borderline Personality Disorder is different regarding the stage of development. It is one of the most common patterns of chronic instability in early adulthood with moments of absence of control at affective and impulsive level, risk of suicide, but it is also true that they tend to diminish gradually through the years. 
Although the tendency to show intense emotions and impulsiveness is chronic, the improvement is observed one year after the treatment and could lead to balanced levels around the 30 - 40 years. In particular, the DSM indicates that most of the individuals will reach stability in their relations at a functional level, there are studies which inform that in a period of more than ten years, more than the half will not show the illness. The Antisocial Personality Disorder would decrease from the age of 40, but the alleviation of the Borderline Personality Disorder could be appreciated before in some individuals. In the legal field, in particular the criminal Spanish one, knowing that the average age of the individuals is between 31 and 40 , we could see a coincidence in the age from which the symptomatology of the Antisocial Personality Disorder and Borderline decreases, as well as the number of prisoners, similarity that shows the link of them to the criminal path.

It will be common for adults with Attention-Deficit and Hyperactivity Disorder and adults with Borderline Personality Disorder to have similar characteristics such as emotional deregulation, impulsiveness, disturbances at cognitive level, as well as the ones related to low self-esteem, problematic social relations, deficit on selfregulation and behaviors related to substance consumption, among other aspects. In this sense, not only adults with Attention-Deficit and Hyperactivity Disorder would have more risk of suffering from a Borderline Personality Disorder at this stage, but taking these conclusions to childhood, the probability that an infant with Attention-Deficit and Hyperactivity Disorder could develop this illness is quite high. However and in spite of the similarities, the differences between them is what lets us treat them as independent from each other. The Borderline Personality Disorder is characterized by a distorted image of themselves, intention, purpose, chronic feelings of emptiness and instability that lead them to be involved in social relationships in an intense but unstable way. The consequences of them would be emotional crisis which could be oriented to abandonment, but also self-harm leading to menaces and suicide ${ }^{28}$, not so typical when there is only diagnosis of Attention-Deficit and Hyperactivity Disorder (Philipsen, 2006).

We can conclude that adults with severe Borderline Personality Disorder could frequently show previous symptoms of ADHD so that the longer persistence in symptomatology of it would benefit comorbidity in Personality Disorders, not ignoring the influence of other features such as the influence of abuses in childhood (Philipsen, Limberger, Lieb, Feige, Kleindients, Ebner-Priemer, Barth, Schmahl, \& Bihus, 2008), where the severity of the symptomatology showed in adults with Borderline Personality Disorder could be influenced by this traumatic experience.

Impulsiveness is again classified as the nuclear aspect between both disorders justifying the evident relation between them although not exempt from divergences regarding the consideration of the origin of this link. Determined selective characteristics of personality would mediate that relation, as it would be the case of this feature linked to aggressiveness, impulsiveness, search of novelties and problems related to conduct in adolescence (Carlotta, Brroni, Maffei, \& Fossati, 2013). We prefer to admit that the symptoms of the Attention-Deficit and Hyperactivity Disorder would be a becoming factor of the development of pathologies in the Cluster B (Speranza, Revah-Levy, Cortese, Falissard, Pham-Scottez, \& Corcos, 2011).

In short, we deduce that inside the Personality Disorders, the Borderline Personality Disorder and the Antisocial Personality Disorder would be the most related to the Attention-Deficit and Hyperactivity Disorder being exactly impulsiveness the connector, not hyperactivity nor the lack of attention, even more as earlier it starts (Mannuzza et al., 1998). Nevertheless, it is true that this feature would benefit the appearance of the said conducts and we also have to consider that determined illnesses such as Substance-Related and Addictive Disorders would emphasize the characteristics of impulsive personality maintaining these conducts and making them chronic and link to the develop of an dysfunctional and pathological personality (Tiffon Nonis, Arroyo Fernández, \& Sarrato Martínez, 2009).

To sum up, it is not strange that we can appreciate impulsiveness as the most common criterion in the APA's Handbook after the clinical significance, which is an aspect indissolubly linked to the diagnosis requirement.

\subsection{Comorbidity as an Essential Risk Factor}

The main point in this last part is to conclude if the presence of aggression and violence in people with an Atten-

\footnotetext{
${ }^{28}$ Different investigations are agreed in admit that suicide could be a conduct presented in ADHD persons, but much of the cases refer that it is because of comorbidity (Putnins, 2005; Belcher, 2013; Plattner, The Kraemer, Williams, Bauer, Kindler, Feucht, Friedrich, \& Steiner, 2007). These last authors indicate that the risk of suffering from a self-victimization process could be even four times higher in person with ADHD than in general population. Besides, they refer that the risk prevalence any time in the life-span course would be greater in womenit isn't strange when we look that the prevalence of Borderline Disorder is higher in this group (Westmoreland, Gunter, Loveless, Allen, Sieleni, \& Black, 2010).
} 
tion-Deficit and Hyperactivity Disorder, evaluating its relationship with the possibility of acting in an antisocial way. More depths, according with this issue, the real question it will be: what about ADHD and criminal career? What happens with delinquency and in which percent it is possible to attribute this trajectory to person with an ADHD diagnosis? When it stars and why continues? Is it due to the presence of a Oppositional Defiant Disorder, Conduct Disorder or Antisocial Personality Disorder or ADHD is enough by itself?

Not according at all with accepting the Attention-Deficit and Hyperactivity Disorder as a cause except by its comorbidity, it is confirmed that its impulsive symptomatology would benefit the criminal path because it coincides with worse illnesses; that is, it is established that an undeniable risk factor would be in people with pathologies but without diagnosis being more difficult to treat the conduct when the malfunction appears. In spite of that the feature would not be a cause itself as the seriousness of the appearance. That would explain the that symptoms of the ADHD have been related to high imprisonment rates ${ }^{29}$, even when the disturbances are linked to driving and risk of self-victimization (e.g. risk of suicide when several emotional features are affected, abuses in childhood, or comorbidity with a Borderline Personality Disorder $)^{30}$.

Apart from that, we consider necessary to refer the importance of driving in individuals with ADHD. Regarding the link with driving - and its hazard, it is concluded that the ADHD is not an obstacle itself for obtaining the driving license but in the presence of cognitive malfunctions or disturbances in the behavior this could mean a risk not only for the person itself but for other drivers (The Royal Australasian College of Psysicians, 2009) ${ }^{31}$. Specifically, the presence of malfunctions for performance would benefit this risk, in car accidents (four times more probable) and seriousness (Barkley, 2004). This is why I agree with the Book (White Book) about the Attention-Deficit and Hyperactivity Disorder publishes in 2013 when it says that the symptoms of the Attention-Deficit and Hyperactivity Disorder have been related to high rates of car accidents in adults and adolescents which gives evidence to the increase of risk of criminality reckless driving would be due to a comorbid Antisocial Personality Disorder or a Substance-Related and Addictive Disorder in adolescence, more than a direct result of the Attention-Deficit and Hyperactivity Disorder where also the possibility of reduction of criminality is mentioned $^{32}$.

According to empirical investigations it is concluded that impulsiveness would be an essential feature when we talk about committing disruptive, antisocial or illicit actions because it would not lead to criminality by itself, there must be other factors. One of the most relevant is the one about empathy and level of emotional intelligence (Piquero, Farrington, Welsh, Tremblay, \& Jennings, 2008) because the absence of altruistic conducts, personal incapacity for social conducts, poor ability for recognising and identifying the regulation of own and others' emotions, lack of personal self-regulation and self-control or the difficulty to accept negative emotions, will benefit these results. We should the influence of different factors into account, at psychobiological and social level to be able to explain criminality but not only in ill people but also in normal delinquents.

One of the most important features in this group is empathy, not being simply the absence of the link empathy-probability of committing crime the fact which would be assessed, but also its influence and consideration regarding other psychological aspects, for example, emotional instability, low self-esteem, rancour, impulsiveness, extroversion, incapacity to have responsibilities and delay reward, absence of feeling of guilt and low to-

\footnotetext{
${ }^{29}$ Attending to the international level, Young, Fitzgerarld and Postma (2013) inform about the high concentration of offenders with ADHD within the Criminal Justice System, referring the additional problems related to comorbidity. Topic that is also discussed by Young, Adamou Grudjonsson, Müller, Pitts, Thome and Asherson (2011) or Connor, Ford, Chapman and Banga (2012).

${ }^{30}$ Regard to the process of self-victimization in ADHD, this circumstance is much more difficult to appear if the person only suffers from a single diagnosis - but not comorbidity, although it is also possible to find its presence in person with a single diagnosis of ADHD. In these situations, impulsivity could be a very relevant factor, although we find other aspects such are mood changes or emotional problems (Putnins, 2005; Philipsen, 2006).

${ }^{32}$ Following the Australian Guidelines on Attention Deficit Hyperactivity Disorder (ADHD) (2009: p. 180 and following), getting the driving licence wouldn't be an impediment neither for ADHD persons nor for whom receive a treatment based on psychostimulants. Nevertheless, it is warned about the risk that could involve inadequate doses, which can lead to a higher aggressive behavior in the driver. On the other hand, it has been appreciated how person with ADHD have severer car accidents or even commit more infringements. To sum up, in general, ADHD is not an inconvenience for getting the driving licence, but it could be recommended assess the capacity and ability in complicated circumstances (e.g. ADHD severe).

${ }^{32}$ As the Expert White Paper on ADHD refers "Symptoms of ADHD have also been associated with relatively high rates of arrests and imprisonment in adulthood and relatively high rates of driving offences in a selected young adult population. Evidence suggests that, in some cases, the increased risk of criminality or risky driving may in fact be attributable to the development of comorbid antisocial or substance use disorders in adolescence, rather than being a direct result of ADHD. Nevertheless, it has been reported that criminality may be reduced by one-third if ADHD is treated". We consider especially relevant this last point because positive prediction of symptoms is a real fact, we mean, most of adults with ADHD live their life in a standardized and harmonized manner—overall when an early diagnostic exists (Young, Fitzgerarld, \& Postma, 2013: p. 7).
} 
lerance to frustration (Koponen, Taiminen, Portin, Himanen, Isoniemi, Heinonen, Hinkka, \& Tenovuo, 2012).

We should not despise the influence of the action of internal features because its effects could be even more catastrophic than the ones defined in external symptomatology, especially regarding cruelty and insulting attitude that could produce in other people. The fact of studying and analysing how certain subjects suppress certain impulsive conducts while others would do the opposite, could allow as to adjust the sense of the treatment according to constitutional principles.

As we can observe, in people with ADHD would be more adequate to talk about the absence of empathy linked to external rather than internal symptomatology because it would be the link absence of empathy-impulsiveness the one that comes from this kind of actions and not the one from the relation absence of empathy-lack of attention. It will be the former the one which would explain the probability that a person with Attention-Deficit and Hyperactivity Disorder will develop other kind of behaviors, these will be: 1) we should talk about the absence of empathy-impulsiveness more than about the disorder itself; 2) the relation is not established directly and in an unequivocal way because impulsive people could be very empathic, this is why we should influence in the assessment of each person independently and individually, as well as later we should take into account other features that could explain this link better (e.g. egocentrism, aggressiveness) (Sánchez Gómez, 2012); and 3) we cannot forget the presence of comorbidity because this is deduced from other illnesses such as the ODD and CD. As we mentioned, this ability (empathy) is registered in the last disorder from 2013.

\section{ADHD and Criminal Justice System: The Worst Consequences of the Persistence of ADHD}

The worst consequences are related to the criminal-penal treatment of the individuals who act against the Law suffering from a mental disorder. It is clear that this definition does not mean that it intercedes, but that we have to assess how it would explain or not the illicit action.

Given the analysis of the Attention-Deficit and Hyperactivity Disorder from its idea and recognition as illness, symptomatology, comorbidity and factors that intervene in its appearance, in this point we will analyze-by a systematic review - the suitability of the presence of the cognitive capacities for whom, suffering from the disorder, act against the Law.

When we have understood the capacity of imputation as capacity of guilt the true question will be about the suitability or not of demanding the eligibility of individuals with the Disorder, that means, would they know what they are doing and would they be able to act according to their decision? Would the knowledge of a similar action be the power to distinguish between good and bad (against the Law)?

To answer the previous questions we analyze the Spanish Criminal Code to assess a possible placement of the Attention-Deficit and Hyperactivity Disorder in some of the statements in which the Text talks about the mental illness (Articles 20 and 21). This is fulfilled with some legal analysis of the Judicial Decisions by Spanish Courts that mention people who acted against the Law suffering from the disorder. Accordign to that, the main hypothesis is: could we accept the ADHD as diminishing or exemption cause of the criminal responsibility? Would its explanation or link be clarified by the Disorder itself or by its co-occurring condition?

\subsection{Preliminary Questions}

The worst consequences of the Pathology do not lead exclusively to the cataloguing of the behaviors or external symptoms regarding the appearance of disruptive disorders, but when those come to antisocial actions previewed in the Law as typical and against it, being able to require guilt to whom do them. It is from this very moment when we can say that the diagnosis, treatment and custody of the patients with these mental disorders suffer the clinical and ethical consequences and also important legal regards, because, depending on its nature, severeness, intensity or duration of the appearance of the symptoms of the illness in the moment of the crime (Carrasco Gómez \& Maza Martín, 2010), so will be the consequence of committing the illicit action.

The examination of the conduct against the Law and assessment of the criminal responsibility will be valued, in any case, about the cognitive and will of the individual. In this context, the mental illness would be one of the nucleus to join Criminal Law and Psychology, the main objective is the analysis of in what measure the mental disorder and under what circumstances are set the assumptions foreseen in the Spanish Criminal Code. Therefore, the question about imputability/non-imputability (imputation or not) in this group, is presented as an essential question to the research on the said collaboration among these branches. In this sense, it would not be un- 
derstandable to apply the assessment of the penal responsibility of the subject without knowing its mental condition which characterized him in the moment of the action (Simon, 2003), considering this way the psychobiological and psychiatric aspects essential for this decision and, afterwards, the criminological features that made easier to do it, that is, turning to the analysis of the aspects coming from the legal and the clinical-forensic environment.

One of the first flaws regarding this, comes from the necessity of putting in place questions related to Law with the worries coming from the diagnosis, because, in most of the moments, the last one will not be enough for the purposes of the former, that is, for appreciating the exemption or reduction of the responsibility and the following measures to be imposed even when the control of the behavior could be understood as a characteristic of the Disorder, the presence of a diagnosis itself will not show that a particular individual would be incapable of controlling his behavior in a certain moment so that the existence of the illness could explain that. We should also add the individual differences that undoubtedly will be in similar illnesses, that is between two subjects that have committed the same action against the Law have the same diagnosis, from which will derive penal responses that could be very diverse, even contradictory.

It is affirmed that the International Classification Disease (ICD) and the DSM are sanitary tools not designed only for its use in the legal environment, there are small references to the forensic environment but that would not justify the dependence of it. Although imputability is capacity of guilt focuses on the cognitive affection and will, the requirements should be set out exclusively in a legal frame and according to the purpose of non-imputability, that is, to these illnesses that due to their own characteristics could show a grade of disturbance in these areas (Mir Puig, 2011). This is why a wrong extrapolation of the diagnosis criteria in non-specific environments which could lead to important legal and penal consequences showing the danger about the risks and limits, this way, it would not depend on these indicators when the existence of a link of enough coincidence would explain the prediction of the behavior at this moment and its following legal determination.

This way, imputability would be the legal word that would make force to relate the pathology to the grade of affection that would explain the action against the Law, besides, the Code only gives information in a negative sense, only talk about non-imputability using examples of its appreciation. It is deduced that the presence of a determined pathology will not necessarily lead to the statement of impunity, being these illnesses which disturbances at cognitive level and will are present at the moment of the illicit action and could be benefited of Articles 20 and 21 of the Spanish Criminal Code (1995).

With this, the aspect is even more relevant if we refer to the premise that not all the disorders registered in the DSM lead to non-imputability when it is so difficult to notice the fact that there are illnesses that are not registered in the main Handbooks; that is, the difficulty about the question of non-imputability is based on the diagnosis born with the DSM, when the decision is so complex for the subjects who have certain symptomatology which precise denomination is not registered in the text. That is, the DSM and the ICD would be consolidated as reference tools of support with an important role in delimiting civil and penal decisions, although they have not been specifically created to orientate legal decisions (they are additional instruments). In other words, the grade of affection of the conscience and will at the moment of the illegal action leads to the determination of the condition of the individual at the moment in which he committed the act against the Law. This circumstance, obviously, surpasses the aim for which the ICD and the DSM were created (Aguilar Cárceles, 2014).

The perceptible neurocognitive aspects in the assessment of exemption and penal reduction come from a mixed system which combines biological and psychological criteria (Cobo del Rosal \& Vives Antón, 1999)33. The mixed system of the Criminal Code is based on a double exigence: i) biopathological cause and ii) a psychic effect, the suppression or severe condition of the capacity to understand the illicit action or to determine the behavior according to this understanding.

\subsection{Criminal Liability: Imputation}

\subsubsection{Requirements: Cognition and Volition}

As we say before, "imputability" is a strictly legal concept which will be measured through the capacity of understanding the action against the Law (cognoscitive factor) and/or the capacity of self-determination according to this understanding (volitive factor), being the aspects related to thought, perception, critical and moral judge-

\footnotetext{
${ }^{33}$ According to that, we recommend to see the judgment of the Spanish Supreme Court about the mixed system used by the Spanish System. More information in: Tribunal Supremo 80/2015, de 6 de febrero de marzo [RJ 2015\515] \& Tribunal Supremo 158/2015, de 17 de marzo [RJ 2015\1991].
} 
ment, the ones which will define the first factor, while the appearance of socially unadapted conducts, such as aggressiveness, impulsiveness, lack of inhibition and social inappropriateness, would be related to will or self-determination. According to that, the assessment of ADHD will be done retrospectively, according to if the neurocognitive disturbance was able to annul or reduce enough the cognition and will, not being enough the current effect but the past one or established at the very moment in which the act against the Law took place. We come from the question if the individual who acted against the Law was able to act in a different way in this situation, that is, according to the Law.

We could concrete the notion of imputability as the capacity of guilt, as motivation of the penal norm, being a personal reproof directed to the individual by doing an action typically against the Law and from which will depend on the countercharge for the proof of the illicit action. In this context, the reproof of the typical conduct against the Law would define imputability as key element of guilt, understanding that this eligibility will only fit among those who know the prohibition and act intentionally or recklessly against it. This is why the incapacity of understanding and self-directing the conduct according to this understanding is deduced from imputability, being this the one that will be defined in the Criminal Code. Regarding negative criteria of identification the individuals that fulfill the circumstances in Articles 20 and 21 are better described and could be benefited at penal level. to sum up, the legal terminology imputability is deduced from the same causes that exclude it, a concept which is not collected neither in the Spanish Constitution nor in most of the foreign Constitutions.

Apart from that, and regarding the current concept of mental disease, we should considerer that it is not possible to follow that one of the characteristics would be the impossibility of knowing what is good and what is bad or to impede that subject acts according to this understanding, where guilt would come from this capacity of knowledge of what is illegal and illicit, so that that could be punishable. This way, says Quintero Olivares that "the subject could understand and assess the process even when he is affected by this incapacity to act according to the positive or negative sense of his actions" and adds "incapacity also present in the usual delinquent” (1999: p. 119).

\subsubsection{Exemption Circumstances in the Spanish Criminal Code Attending to the Presence of Psychical Pathologies}

Departing from a qualitative, quantitative, chronological and causal criterion (Carrasco Gómez \& Maza Martín, 2010) to notice enough the reduction, limit or even annulment of the capabilities, the Criminal Code of 1995 has two specific chapters for the observation of the circumstances of exemption and lessening of that criminal responsibility (Section I of the First Book). In particular, in the three first parts of Chapter Two "The causes that exempt from criminal responsibility" (Article 20) the pathological coincidences in the appreciation of impunity are mentioned directly, having already noticed that the deduction of the term non-imputability would be established regarding the causes for the exemption of responsibility or the opposite to imputability, this will not always be seen in absolute terms (Article 21 of the Spanish Criminal Code). This way, if imputability is measured by the cognitive capacity and will, the non-imputability will be measured by the incapacity of understanding and impossibility of willing to act according to this understanding. We are going to analyze ADHD according to its link with the exemption circumstances.

According to the Article 20.1 of the Spanish Criminal Code, the reform that was taken in 1983 of the Criminal Code of 1973 leads to the substitution of the expression "mental alienation" for "psychic defect" differentiating in the same Article between the permanent mental defects and transient mental disorder.

Inside the first group we can see four sections to Oligophrenia, Neurosis, Psychosis, and Psychopathies, that in spite of being described inside the circumstances of exemption, we have to take into account the sentences like being able to admit that it will be exceptional the assumptions that see them in this sense, regarding the last group which is known as the one of Personality Disorders (Fonseca Morales, 2009; Muñoz Conde \& García Arán, 2010; Orts Berenguer \& González Cussac, 2010).

The main question would be address to know if a person with ADHD could be applied some of the circumstances foreseen in the Article 20.1 of the Criminal Code, which requires the knowledge about if the capacities of understanding an illicit action are really affected. If the circumstances under which the action took place were due to a mental defect, or if there were comorbid disorders that would have affected the action against the Law, we should assess until what extent both aspects (cognition and will) would be binded to impunity ${ }^{34}$.

\footnotetext{
${ }^{34}$ In this sense, we can appreciate the judgment of the Spanish Supreme Court that indicates that impunity is only possible when the person with a mental diagnosis has absolutely annulled its cognitive and volitive faculties. More information in: Tribunal Supremo 120/2014, de 26 de febrero [RJ 2014\928].
} 
The presence and treatment of the Attention-Deficit and Hyperactivity Disorder in Spanish Courts have been controversial and more if we take into account that in many occasions it is used this term as synonym of other mental illnesses which will result in the equal process for very different disorders. Regarding this point, would its inclusion be possible? For this, we have to look at the non-imputability observed by diagnosed co-occurrence when there is any of the disorders mentioned in Article 20.1 of the Criminal Code, that is, Oligophrenia, Psychosis, Neurosis or Psychopathies, knowing that in these cases it would be difficult to consider the grounds for exemption only in special cases, especially regarding to Personality Disorders and Substance-Related and Addictive Disorder (Article 20.2).

In relation to the Article 20.2 of the Spanish Criminal Code, full intoxication and Abstinence Syndrome are supported by the influence of pathobiological factors and psychologic effect of this condition, that is, due to intake or lack of the substance, the individual will not have the capacity of understanding and acting by himself.

In the case of the ADHD, impulsive actions could lead to action without thinking enough about the consequences or results, which does not mean that the subject does not have enough capacity to distinguish between good and bad; capacity that could be requested from a legal point of view. This malfunction of will could lead to unexpected, very fast responses and sometimes to violence or excessive brutality, noticing it especially in individuals with Personality Disorders, patients with brain damage, or as a consequence of the use of drugs ${ }^{35}$, appearing also in normal individuals without pathology or symptomatology.

The best option in individuals with ADHD to apply this exemption would be from the co-occurrence of this condition in people with this diagnosis, that is, knowing that the impulsive symptomatology is a characteristic of them, as well as the possible comorbidity given with the Substance-Related and Addictive Disorder, we understand that this feature could make easier the use of drugs until producing the described effects to apply non-imputability.

In spite of that, we should not forget that the symptom lack of attention in the Attention-Deficit and Hyperactivity Disorder will be the most chronic or long-term condition, decreasing the symptoms related to hyperactivity and impulsiveness from which would be right to consider the result of exemption due to intoxication or absence described. Besides, not only the Attention-Deficit and Hyperactivity Disorder would be a risk factor in binding consumption-delinquency, but also other illnesses that could appear in a co-occurrent way ${ }^{36}$.

Following with the Article 20.3 of the Spanish Criminal Code, this precept shows the non-imputability as a consequence of the loss or ignorance of the legal sense of the own actions regarding sensory defects. A reflection that would be made regarding will point out the exemption that would be suitable to notice the classification of Schizophrenia because the first and third points in Article 20 of the Criminal Code could be placed as disorder or symptom. In this sense, maybe it would be suitable to know about the assumptions under this section. In spite of that, the importance of the Schizophrenia Spectrum and other Psychotic Disorders makes that they would be bound with Article 20.1 of the Criminal Code.

In its relation to the ADHD the assessment of this section cannot be concluded because it is not understood that this diagnosis could show disturbances or sensorial defects itself that could exempt from liability the subject who, protected by this diagnosis, did the illicit action. It would be different to prove the fact that the absence or severe defect of vital experiences and knowledge of social rules and other circumstances that have taken away enough sensorial capacity of the subject to affect him cognitively, when the subject suffers from Attention-Deficit and Hyperactivity Disorder or other mental illness.

\subsubsection{Attenuating Circumstances in the Spanish Criminal Code Attending to the Presence of Psychical Pathologies}

Regarding Chapter III of the same book and section, the Criminal Code of 1995 in its Article 21 points out the circumstances of reduction of criminal liability. In particular, as diminished imputability would be applied this benefit to whom show some of the aspects in this Article of the Criminal Code, understanding that there would be a lack of balance between cognition and will.

From the mitigating circumstances that could be more important due to the mental condition of the subject,

\footnotetext{
${ }^{35} \mathrm{Apart}$ from that, it is important to remember that drug consumption is strongly linked to drug-trafficking, which are two aspects that have a strong presence in the Penitentiary System and that even concern to the international level with relevant consequences. In this last sense, Williams indicates that "the war on drugs has grown to become a major pillar of US foreign policy" (Williams, 2015: p. 103).

${ }^{36}$ But even in these situations we have to show that comorbidity illnesses are severe enough to provoke significant dysfunctions in the person In Spain, several Provincial Court’s judgments confirm this fact, for example: Sentencia de la Audiencia Provincial de Castellón de 29 de octubre de 2013 [JUR 2014\120484].
} 
the most relevant would be the one described in part two of Article 21 of the Criminal Code. This way, Addiction as a mitigation in its possible bind with Attention-Deficit and Hyperactivity Disorder would be established from the same premises that in previous paragraphs; this is, the possibility of appearance with this kind of pathologies. Moreover, we could notice a stronger link with the method used by the legislator for the treatment of the drug addict. We understand with this that continuity in the pathology requested in this case, joined with a possible co-occurrence with the Attention-Deficit and Hyperactivity Disorder could lead to a bigger probability to understand the link between these disorders. Thus, while in the case of exemption we use the word "condition", in the case of Article 21 "severe addiction" is used, which will be understood as a repeating behavior of the individual.

From the risk factors that, if they were part of the Attention-Deficit and Hyperactivity Disorder they would be indicators of the criminal path, one of them would be the use of drugs that could be the result of the same symptoms of the disorder, failure or school abandonment, rejection from a group and search for mechanisms to go away from these situations, among other aspects. Moreover, if we add to the chronicity of the pathology a long-term consumption of substances, the appearances of several conduct disorders, apart from the illnesses, would not be strange. These would lead to antisocial behaviors. Those are the same behaviors that would provoke the clinical relapse and penal reoccurrence. The penalty could be reduced if he is a long-term drug addict.

The question is established about drug addiction which does not prevent the disorders from influencing the classification but they will have the points foreseen in the Criminal Code by themselves because the effect of the terms required for non-imputability and half of the imputability is not considered.

On the other hand, fury or obstinacy (article 23.1 of the Criminal Code) or any other circumstance of similar importance (21.7), could be applied to any individual without the necessity of the diagnosis of the Attention-Deficit and Hyperactivity Disorder. Nevertheless, as we have seen in previous points, the feature impulsiveness would be a risk indicator for the notice of these circumstances.

\subsection{Has an Accused Person with Diagnosis of ADHD the Same Criminal Liability That Other Offenders Have?}

Translating which title means, in this point we raise the following question: Are their cognitive and volitive symptoms severe enough to don't let us demand responsibility from their antisocial and criminal acts? Are they considered as imputable or non-imputable individuals? What can we deduct from the criminal penal doctrine, from the Spanish Courts and from the Spanish Cirminal Code?

After this analysis we can affirm that in any aspect of the Code the appearance of this concrete mental disorder is reflected, apart from the mention to other disorders in three sections of Article 20 of the Criminal Code and the others in Article 21. This way, the only aspect that an individual with Attention-Deficit and Hyperactivity Disorder could reach is that the characteristic symptomatology of the disorder is bound to some of them by co-occurrence in other disturbances (Aguilar Cárceles, 2014) but, as we said, not necessarily existing differences regarding other individuals of the normal population.

One of the hardest questions could come from the analysis of wording the Criminal Code because we would mention "the one who cannot understand the illicit fact or act according to this understanding". The dilemma warns that the absence of both faculties is not a sine qua non requirement, but will is hardly represented when the cognition fails. Regarding the Attention-Deficit and Hyperactivity Disorder, it would be will the area we believe to be affected and not the capacity of understanding but, until what extent could we say that the capacity of self-determination would not be modified by the subject?

In the case of the Attention-Deficit and Hyperactivity Disorder, we would not defend the fact that the cognitive style of the patient would be affected enough to be unable to differentiate between good and bad according to the Law (Morillas Fernández, 2013; Aguilar Cárceles, 2014). In general, we do not see the effect on attention as a feature that could lead to non-imputability, the question regarding attention, will depend on the level of severity on the individual, because in the case of being extreme, there would be a maximum of incapability to differentiate between reality and the outside world, so that we would have to talk about a different pathology from the Attention-Deficit and Hyperactivity Disorder, because, as the name indicates, there is a deficit of attention.

The malfunction would be focused on a deficit and not in a disturbance severe enough to eliminate the attentive faculties, especially cognition and will. Moreover, we must not forget that the development of the brain, which is different in the first years of life, will be normalized from adolescence, reason which will not support a 
stable or permanent disturbance.

The biggest questions come from the aspect of willpower, the capacity of self-determination. Nevertheless, the issue of concreting the sense in which the external symptomatology hyperactive-impulsive would be very complex, especially when it comes from other illnesses recognised by the Code but which symptomatology (impulsive) would be very discussed, such as in the case of Personality Disorders or the Substance-Related and Addictive Disorders being considered mainly not enough moments for noticing a reduction of culpability. Moreover, in a lot of assumptions like the mitigation due to similarity would not be noticed the consideration of a symptomatology of the type impulsive-aggressive not enough to conclude the disturbance of the willingness.

At this point and following the basis that from the first considerations of the disorder, a special relevance is given to the consideration if the existence or not of enough inhibiting will (impulsive symptomatology), where the true reason for the relation of the antisocial conducts would have to be looked for regarding impulsiveness. In particular, to delimit the existence of a causal relation, we should assess if the interaction between the main characteristics of personality and the charged action follows a pattern of usual behavior in this pathology, being also enough to explain the cognitive and volitive effect during the illicit action ${ }^{37}$.

\section{Conclusion and Further Discussions}

The bound with criminal path or punishable actions from a criminal field has been reinforced by the same reference that the DSM admits about the link of the disorder with the development of Conduct Disorders in adolescence that could lead to an Antisocial Personality Disorder and that would increase the risk of use of drugs and higher probability of imprisonment due to the own definition of the individual.

The true factors in the analysis of imputability refer to biological aspects that sheltering in most of the disorders that characterise the exemption of criminal liability to admit a severe disturbance or enough to find impunity. Specifically, we could say that it would be from these conditions when the question of non-imputability would present less questions for its application (e.g. Schizophrenia).

In the assessment of imputability maybe it would be more suitable to talk about the symptomatological link of the Attention-Deficit and Hyperactivity Disorder instead about the disorder itself, because in any case it would be the aspect related to self-determination (will on the subject to do certain actions), the one which will agree more with non-imputability. In spite of that, from the legal revision could be deduced that it could be appreciated according to the existence of hyperactive-impulsive symptoms, noticing again the exchange in a description that, in most of the cases, will be linked to the second of the features.

This way, it would not be possible to establish the escalation of non-imputability in the individual with diagnosis of Attention-Deficit and Hyperactivity Disorder but in the symptomatology and comorbidity. In general terms, imputability and impunity are more than legal questions, and, although they would have to do a lot with mental illnesses, only its idea could be seen as a filter in determining the criminal benefit foreseen in Articles 20 and 21 of the Criminal Code.

According to this, could be true or admissible to indicate that the exclusion of the action against the Law excludes guilt, because this individual represents a case of non-imputability; that is, the author of a typical fact considered punishable when the requirements of the Criminal Code are fulfilled, there will be an exemption of the criminal liability he could get due to consider some of the requirements in this Article 20. This is why we would say that doing a typical action would not be enough to determine guilt, because we also should notice the absence of some of the circumstances foreseen in the Criminal Code. From them, we could talk about act against the Law and no exigence of criminal liability.

Regarding the question if the Attention-Deficit and Hyperactivity Disorder would be enough by itself to affect cognitive capacities and willingness of whom commits illicit action, from this statement it would be possible to talk about changeable circumstances in the criminal liability foreseen in the Criminal Code. But even though we are agreeing in considering that there is an obvious explanation based on neuroanatomical, neurochemical and genetic aspects to understand the disorder, the essential question is focused on the level in which they will have affected their cognitive and will faculties.

Regarding to Attention-Deficit and Hyperactivity Disorder, the legal system shows that the individual with

\footnotetext{
${ }^{37}$ In this point, should be important to considerer that different types of research studies link the ADHD in the minor with the possibility of developing antisocial behavior once they saw and experienced mistreatment in the domestic and family circle. In Spain, several Provincial Court's judgments confirm this fact, for example: Sentencia de la Audiencia Provincial de Salamanca 2/2014, de 4 de marzo [JUR 2014। 98142] \& Sentencia de la Audiencia Provincial de Alicante 829/2012, de 20 noviembre [ARP 2013184].
} 
this illness is completely aware of the illicit action, he can distinguish between the prohibition or not of the conduct according to Law there is normally no relevant effect in the cognoscitive capacity. On the other hand, the possibility of noticing any of the circumstances of non-imputability will be higher regarding the impulsive symptommatology, the question would be diverted to the aspect of willingness. Although we know that the Article 20.1 of the Criminal Code mentions the dilemma of understanding or acting according to this understanding, it would be reasonable to set the question about the Attention-Deficit and Hyperactivity Disorder regarding the second of the capacities, not the first one.

According to the treatment of ADHD subjects inside the Spanish Criminal System, we can admit that: a) the only option to take into account the mitigation of imputability — not annulment—would be related to the effect on willingness and possible absence of control by the individual; b) that we do not understand the external symptomatology as cause to obtain this benefit more than to other criminals without mental illness; c) in very special cases this has been applied due to similarity, being these assumptions explained by the co-occurrent pathology and not by the disorder itself; and d) as any other disorder, prevention continue being the best way to avoid criminality, over all in pathologies with severe consequences ${ }^{38}$.

To sum up, the risk of the Attention-Deficit and Hyperactivity Disorder in the criminal path is measured from the impulsive symptomatology that in its link to other disorders, mainly Oppositional Defiant Disorder, Conduct Disorder, Antisocial Personality Disorder and Substance-Related and Addictive Disorder, which are the group with legal effects that could be in an individual without important disturbance. If the causal explanation is not linked to the external conditions or characteristics of the disorder at the moment of the illicit action, we will tend to admit that there would be no disturbance enough for non-imputability nor regarding the cognitive and volitional capacities.

\section{References}

Academy of Pediatrics (2000). Clinical Practice Guidelines: Diagnosis and Evaluation of the Child with Attention-Deficit/ Hyperactivity Disorder. Pediatrics, 105, 1158-1170. http://pediatrics.aappublications.org/content/105/5/1158

Aguilar Cárceles, M. M. (2013). La influencia del contexto familiar en el desarrollo de Conductas violentas durante la adolescencia: Factores de riesgo y protección. Revista Criminalidad, 54, 27-46.

Aguilar Cárceles, M. M. (2014). El Trastorno por Déficit de Atención e Hiperactividad (TDAH). Aspectos jurídico-penales, psicológicos y criminológicos. Madrid: Dykinson.

Aguilar Cárceles, M. M., \& Godoy Fernández, C. (2013). Niveles de empatía, Inteligencia emocional e Impulsividad en sujetos en Régimen Penitenciario Abierto. In F. Expósito, I. Valor-Segura, M. Vilariño, \& A. Palmer (Eds.), Psicología Jurídica Aplicada a los Problemas Sociales (pp. 237-244). Colección Psicología y Ley №. 11. Sociedad Española de Psicología Jurídica y Forense.

Aguilar Cárceles, M. M., Godoy Fernández, C., Sánchez-Meca, J., Martínez-Hernández, M., \& Laosa Jiménez, S. (2011). Nivel de impulsividad en una muestra penitenciaria con diagnóstico de Trastorno Antisocial de la Personalidad. Libro de IX Congreso Nacional de Psicología Clínica. San Sebastián.

Álvarez, H. K., \& Ollendick, T. H. (2003). Individual and Psychosocial Risk Factors. In C. A. Essau (Ed.), Conduct and Oppositional Defiant Disorders. Epidemiology, Risk Factors, and Treatment. New Jersey: Lawrence Erlbraum Associates.

American Psychiatric Association (APA) (2013). Diagnostic and Statistical Manual of Mental Disorders, Fifth Edition (DSM-5). Washington DC.

Babinski, L. M., Hartsough, C. S., \& Lambert, N. M. (1999). Childhood Conduct Problems, Hyperactivity-Impulsivity, and Inattention as Predictors of Adult Criminal Activity. Journal of Child Psychology and Psychiatry, 40, 347-355. http://dx.doi.org/10.1111/1469-7610.00452

Bansal, R., Staib, L. H., Laine, A. F., Hao, X., Xu, D., Liu, J., Weissman, M., \& Peterson, B. S. (2012). Anatomical Brain Images Alone Can Accurately Diagnose Chronic Neuropsychiatric Illnesses. Neuro-Mapping and Therapeutics: A Collection from PLOS ONE, 7, 1-21. http://journals.plos.org/plosone/article?id=10.1371/journal.pone.0050698 http://dx.doi.org/10.1371/journal.pone.0050698

Barbudo, E., Correas, J., \& Quintero, F. J. (2009). Caracteriología del adulto con trastorno por déficit de atención e hiperactividad. In F. J. Quintero, J. Correas, \& F. J. Quintero (Eds.), Trastorno de déficit de atención e hiperactividad

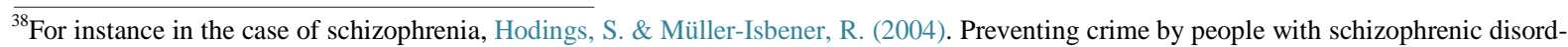
ers: the role of psychiatric services. The British Journal of Psychiatry Aug 2004, 185 (3), 245-250. Besides that, we would like to add that apart from the typical ways of committing a crime, the mass media and "Internet" have encourage the delinquents to use them for its facilities in the moment of carried out the crime (for example: anonymity). Nevertheless, is it true that criminal law culture has higher rates when delinquents commit the crime using those tools? Question discussed by Caterini (2015: p. 57).
} 
(TDAH) a lo largo de la vida (3ºdición). Madrid: Elsevier Masson.

Barkley, R. A. (2004). Driving Impairments in Teens and Adults with Attention-Deficit/Hyperactivity Disorder. Psychiatric Clinics of North America, 27, 233-260. http://dx.doi.org/10.1016/S0193-953X(03)00091-1

Barkley, R. A. (2006). Primary Symptoms, Diagnostic Criteria, Prevalence, and Gender Differences. In R. A. Barkley (Ed.), Attention-Deficit Hyperactivity Disorder. A Handbook for Diagnosis and Treatment (3rd ed., p. 81). London: The Guildford Press.

Barkley, R. A., Murphy, K. R., \& Fischer, M. (2009). El TDAH en adultos. Lo que nos dice la ciencia. Madrid: J\&C Ediciones Médicas.

Barkly, R. A. (2014). http://www.abc.es/familia-padres-hijos/20140201/abci-escuela-online-201401241242.html

Barrickman, L., Noyes, R., Kuerman, S., Schumacher, E., \& Verda, M. (1991). Treatment of ADHD with Fluoxetine: A Preliminary Trial. Journal of American Academy of Child \& Adolescent Psychiatry, 30, 762-767. http://dx.doi.org/10.1097/00004583-199109000-00010

Bartol, C. R. (2006). Resilience and Antisocial Behaviour. In C. R. Bartol, \& M. A. Bartol (Eds.), Current Perspectives in Forensic Psychology and Criminal Justice. London: Sage Publication.

Belcher, J. R. (2013). Towards More Effective Behavioral Interventions in the Prison Setting. International Journal of Offender Therapy and Criminology, 57, 131-132. http://dx.doi.org/10.1177/0306624X12471931

Biederman, J., Mick, E., \& Faraone, S. V. (2000). Age-Dependent Decline of Symptoms of Attention Deficit Hyperactivity Disorder: Impact of Remission Definition and Symptom Type. American Journal of Psychiatry, 157, 816-818.

http://dx.doi.org/10.1176/appi.ajp.157.5.816

Biederman, J., Wilens, T. E., Mick, E., Spencer, C., \& Faraone, S. V. (1995). Psychoactive Substance Use Disorders in Adults with Attention-Deficit/Hyperactivity Disorder (ADHD): Effects of ADHD and Psychiatric Comorbidity. American Journal of Psychiatry, 152, 1652-1658. http://dx.doi.org/10.1176/ajp.152.11.1652

Biederman, J., Wilens, T. E., Mick, E., Spencer, C., \& Faraone, S. V. (1999). Pharmacotherapy of Attention-Deficit/Hyperactivity Disorder reduces Risk for Substance Use Disorder. Pediatrics, 104, 1-5. http://dx.doi.org/10.1542/peds.104.2.e20

Biederman. J., \& Spencer, T. (1999). Attention-Deficit/Hyperactivity Disorder (ADHD) as a Noradrenergic Disorder. Biological Psychiatry, 46, 1234-1242. http://dx.doi.org/10.1016/S0006-3223(99)00192-4

Boyle, M., \& Lipman, E. L. (2002). Do Places Matter?: Socioeconomic Disadvantage and Behavioral Problems of Children in Canada. Journal of Consulting and Clinical Psychology, 70, 378-389. http://dx.doi.org/10.1037/0022-006X.70.2.378

Brenner, A. (1977). A Study of the Efficacy of the Feingold Diet on Hyperkinetic Children. Clinical Pediatric, 16, $652-656$. http://dx.doi.org/10.1177/000992287701600715

Carlotta, D., Brroni, S., Maffei, C., \& Fossati, A. (2013). On the Relationship between Retrospective Childhood ADHD Symptoms and Adult BPD Features: The Mediating Role of Action-Oriented Personality Traits. Comprehensive Psychiatry, 54, 943-952. http://dx.doi.org/10.1016/j.comppsych.2013.03.025

Carrasco Gómez, J. J., \& Maza Martín, J. M. (2010). Tratado de Psiquiatría Legal y Forense. Madrid: La Ley.

Castejón, J. I. (2011). Experiencias en TDAH y sus comorbilidades. Selección de trabajos originales del programa de experiencias clínicas en TDAH y sus comorbilidades. Madrid: Draft Editores.

Castellanos, F. X., Giedd, J. N., Berquín, P. C., Walter, J. M., Sharp, W., Tran, T., Vaituzis, K., Blumenthal, J. D., Nelson, J., Bsatain, T. M., Zijdebons, A., Evans, A. C., \& Rapoport, J. L. (2001). Quantitative Brain Magnetic Resonance Imaging in Girls with Attention-Deficit/Hyperactivity Disorder. Archives of General Psychiatry, 58, 289-295.

http://dx.doi.org/10.1001/archpsyc.58.3.289

Castellanos, F. X., Lee, P. P., Sharp, W., Jeffries, N. O., Greenstein, D. K., Clasen, L. S., Blumenthal, J. D., James, R. S., Ebens, C. L., Walter, J. M., Zijdenbos, A., Evans, A. C. C, Giedd, J. N., \& Rapoport, J. L. (2002). Developmental trajectories of Brain Volume Abnormalities in Children and Adolescents with Attention-Deficit/Hyperactivity Disorder. Journal of the American Medical Association, 288, 1740-1748. http://dx.doi.org/10.1001/jama.288.14.1740

Caterini, M. (2015). Criminal Risk, Media Representation and Role of the Criminal Law Culture. Beijing Law Review, 6, 55-68. http://dx.doi.org/10.4236/blr.2015.61008

Cobo del Rosal, M., \& Vives Antón, T. S. (1999). Derecho Penal. Parte General (4ª ed.). Valencia: Tirant lo Blanch.

Comings, D. E. (2001). Clinical and Molecular Genetics of ADHD and Tourette Syndrome: Two Related Polygenic Disorders. Annals New York Academy of Sciences, 931, 50-83. http://dx.doi.org/10.1111/j.1749-6632.2001.tb05773.X

Comings, D. E., Gade-Andavolu, R., Gonzalez, N., Wu, S., Muhleman, D., Blake, H., Dietz, G., Saucier, G., \& MacMurray, J. P. (2000). Comparison of the Role of Dopamine, Serotonin, and Noradrenaline Genes in ADHD, ODD and Conduct Disorder: Multivariate Regression Analysis of 20 Genes. Clinical Genetics, 57, 178-196. http://dx.doi.org/10.1034/j.1399-0004.2000.570304.x 
Connor, D. F., Ford, J. D., Chapman, J. F., \& Banga, A. (2012). Adolescent Attention Deficit Hyperactivity Disorder in Secure Treatment Settings. Criminal Justice and Behavior, 39, 726-730. http://dx.doi.org/10.1177/0093854812437015

Cortese, S., Faraone, V., \& Sergeant, J. (2011). Misunderstandings of the Genetics and Neurobiology of ADHD: Moving Beyond Anachronisms. American Journal of Medical Genetics Part B: Neuropsychiatric Genetics, 156, 513-516. http://dx.doi.org/10.1002/ajmg.b.31207

Cross-Disorder Group of Psychiatric Genomics Consortium (2013). Genetic Relationship between Five Psychiatric Disorders Estimated from Genome-Wide SNPs. Nature Genetics, 45, 984-994. http://dx.doi.org/10.1038/ng.2711

Derks, E. M., Hudizak, J. J., \& Boomsma, D. I. (2009). Genetics of ADHD, Hyperactivity, and Attention Problems. In Y. K. Kim (Ed.), Handbook of Behavior Genetics (pp. 361-378). New York: Springer. http://dx.doi.org/10.1007/978-0-387-76727-7_25

Edwards, A. C., \& Kendler, K. (2012). Twin Study of the Relationship between Adolescent Attention-Deficit/Hyperactivity Disorder and Adult Alcohol Dependence. Journal of Studies on Alcohol and Drugs, 73, 185-194. http://dx.doi.org/10.15288/jsad.2012.73.185

Everitt, B. J., Belin, D., Economiduo, D., Pelloux, Y., Dalley, J. W., \& Robbins, T. W. (2008). Neural Mechanisms Underlying the Vulnerability to Develop Compulsive Drug Seeking Habits and Addiction. Biological Sciences, 363, 3125-3135. http://dx.doi.org/10.1098/rstb.2008.0089

Faraone, S. V., Biederman, J., Spence, T., Wilens, T., Siedman, L. J., Mick, E., \& Doyle, A. E. (2000). Attention-Deficit/ Hyperactivity Disorder in Adults: An Overview. Biological Psychiatry, 48, 9-20.

http://dx.doi.org/10.1016/S0006-3223(00)00889-1

Faraone, S. V., Biederman, J., Spencer, T. J., \& Aleardi, M. (2006). Comparing the Efficacy of Medications for ADHD Using Meta-Analysis. Medscape General Medicine, 8, 1-4. http://www.ncbi.nlm.nih.gov/pmc/articles/PMC1868385/

Farrington, D. P. (1992). Juvenile Delinquency. In J. C. Coleman (Ed.), The School Years (2nd ed.). London: Routledge.

Farrington, D. P. (2009). Psychosocial Causes of Offending. In M. G. Gelder, N. C. Andreasen, J. J. López-Ibor Jr., \& J. R. Geddes (Eds.), New Oxford Textbook of Psychiatry (2nd ed.). Oxford: Oxford University Press.

Farrington, D. P., \& Welsh, B. (2007). Saving Children from Life of Crime. Early Risk Factors and Effective Interventions. Oxford University Press.

Federación Española de Asociaciones de Ayuda al Déficit de Atención e Hiperactividad (FEAADAH). http://www.feaadah.org/es

Filipek, P. A., Serud-Chilikeman, M., Steingard, R. J., Renshaw, P. F., Kennedy, D. N., \& Biederman, N, J. (1997). Volumetric MRI Analysis Comparing Subjects Having Attention-Deficit Hyperactivity Disorder with Normal Controls. Neurology, 48, 589-601. http://dx.doi.org/10.1212/WNL.48.3.589

Fletcher, J. M. (2013). The effects of Childhood AHD on Adult Labor Market Outcomes. The National Bureau of Economics Research, 11, 2013. National Bureau of Economics Research (NBER): www.nber.org http://dx.doi.org/10.3386/w18689

Fletcher, J., \& Wolfe, B. (2009). Long-Term Consequences of Childhood ADHD on Criminal Activities. The Journal of Mental Health Policy and Economics, 12, 119-138. http://dx.doi.org/10.2139/ssrn.1489147

Fonagy, P., Target, M., Cottrell, D., Phillips, J., \& Kurtz, Z. (2003). What Works for Whom? London: The Guilford Press.

Fonseca Morales, G. M. (2009). La anomalía o alteración psíquica como eximente o atenuante de la responsabilidad criminal. Madrid: Dykinson.

Franke, B., Faraone, S. V., Asherson, P., Bitelaar, J., Bau, C. H., Ramos-Quiroga, J.A., Mick, E., Grevet, E. H., Johansson, S., Haavik, J., Lesch, K. P., Cormand, B., \& Reif, A. (2012). The Genetics of Attention Deficit/Hyperactivity Disorder in Adults, a Review. Molecular Psychiatry, 17, 960-987. http://dx.doi.org/10.1038/mp.2011.138

Froehlich, T. E., Mc Cough, J. J., \& Stein, M. A. (2010). Progress and Promise of Attention-Deficit Hyperactivity Disorder Pharmacogenetics. CNS Drugs, 24, 99-117. http://dx.doi.org/10.2165/11530290-000000000-00000

Getahun, D., Rhoads, G. G., Demissie, K., Lu, S. E., Quinn, V. P., Fassett, M. J., Wing, D. A., \& Jaacobsen, S. J. (2013). In Utero Exposure to Ischemic-Hypoxic Conditions and Attention-Deficit/Hyperactivity Disorder. Pediatrics, 131, 53-61. http://dx.doi.org/10.1542/peds.2012-1298

Goldstein, S. (2002). Continuity of AHD in Adulthood: Hypothesis and Theory Meet Reality. In S. Goldstein, \& A. T. Ellison (Eds.), Clinician's Guide to Adult ADHD: Assessment and Intervention. San Diego: Academics Press.

Gratch, L. O. (2009). El trastorno por déficit de atención (ADD-ADHD). Clínica, Diagnóstico y tratamiento en la infancia, la adolescencia y la adultez ( ${ }^{a}$ Edición). Buenos Aires: Panamericana.

Halmoy, S., Klungsoyr, K., Skjaeren, R., \& Haavik, J. (2012). Pre- and Perinatal Risk Factors in Adults with Attention-Deficit/Hyperactivity Disorder. Biological Psychiatry, 71, 474-481. http://dx.doi.org/10.1016/j.biopsych.2011.11.013 
Hodings, S., \& Müller-Isbener, R. (2004). Preventing Crime by People with Schizophrenic Disorders: The Role of Psychiatric Services. The British Journal of Psychiatry, 185, 245-250. http://dx.doi.org/10.1192/bjp.185.3.245

Hoffman, H. (1844). The Story of Fidgety Philip. Virginia: Commonwealth University.

Hurting, T., Ebeling, H., Taanila, A., Miettunen, J., Smalley, S. L., McCough, J. J., Loo, S. K., Marjo-Rittaja, D., \& Moilanem, I. (2007). Symptoms and Subtypes: Relationship between Childhood and Adolescent Symptoms. Journal of the American Academy of Child \& Adolescent Psychiatry, 46, 1605-1613. http://dx.doi.org/10.1097/chi.0b013e318157517a

Insel, T. (2010). Director’s Blog: Brain Scans—Not Quite Ready for Prime Time. National Institute of Mental Health, 7. http://www.nimh.nih.gov/about/director/2010/brain-scans-not-quite-ready-for-prime-time.shtml

King's College-Social, Genetic \& Developmental Psychiatry Centre (MRC). http://www.kcl.ac.uk/iop/depts/mrc/research

Knetch, A., Snijders, T. A. B., Baerveldt, C., Steglich, C. E. G., \& Raub, W. (2010). Friendship and Delinquency: Selection and Influence Processes in Early Adolescence. Social Development, 19, 494-514. http://dx.doi.org/10.1111/j.1467-9507.2009.00564.x

Kolar, D., Keller, A., Golfinopoulos, M., Cumyn, L., Syer, C., \& Hechtman, L. (2008). Treatment of Adults with Attention-Deficit/Hyperactivity Disorder. Journal of Neuropsychiatric Disease and Treatment, 4, 389-403.

Koponen, S., Taiminen, T., Portin, R., HImanen, L., Isoniemi, H., Heinonen, H., Hinkka, S., \& Tenovuo, O. (2012). Axis I and II Psychiatric Disorders after Traumatic brain Injury: A 30 Years Follow-Up Study. American Journal of Psychiatry, 159, 1315-1321. http://dx.doi.org/10.1176/appi.ajp.159.8.1315

Krain, L., \& Catsellanos, F. X. (2006). Brain Development and ADHD. Clinical Psychology Review, 26, $433-444$. http://dx.doi.org/10.1016/j.cpr.2006.01.005

Kreager, D. A. (2004). Strangers in the Hall: Isolation and Delinquency in School Networks. Social Forces, 83, 351-390. http://dx.doi.org/10.1353/sof.2004.0117

Lahey, B. B., Mc Burnett, K., \& Loeber, R. (2000). Are Attention-Deficit/Hyperactivity Disorder and Oppositional Defiant Disorder Developmental Precursors o Conduct Disorder? In A. J. Sameroff, M. Lewis, \& S. M. Miller (Eds.), Handboook of Developmental Psychopatlogy (2nd ed.). New York: Kluwer Academic/Plenum Publishers. http://dx.doi.org/10.1007/978-1-4615-4163-9_23

Lee, S. S., Humprheys, K. L., Flory, K., Liu, R., \& Glas, K. (2011). Prospective Association of Childhood Attention-Deficit/ Hyperactivity Disorder (ADHD) and Substance Use and Abuse/Dependence: A Meta-Analytic Review. Clinical Psychological Review, 31, 328-341. http://dx.doi.org/10.1016/j.cpr.2011.01.006

Loeber, R., \& Farrington, D. P. (2001). Significance of Child Delinquency. In R. Loeber, \& D. P. Farrington (Eds.), Child Delinquents: Development, Interventions, and Service Needs. London: London Sage Publications. http://dx.doi.org/10.4135/9781452229089.n1

Loeber, R., Burke, J. D., \& Lahey, B. B. (2002). What Are Adolescent Antecedents to Antisocial Personality Disorder? Criminal Behavior and Mental Health, 12, 24-36. http://dx.doi.org/10.1002/cbm.484

Loeber, R., Burke, J. D., Lahey, B. B., Winters, A., \& Zera, M. (2000) Oppositional Defiant and Conduct Disorder: A Review of the Past 10 Years, Part I. Journal of the American Academy of Child and Adolescent Psychiatry, 39, 1468-1484. http://dx.doi.org/10.1097/00004583-200012000-00007

Loney, J. (1998). Substance Abuse in Adolescents: Diagnostic Issues from Studies of Attention Deficit Disorder with Hyperactivity. NIDA Research Monographs, 77, 19-26.

López Soler, C., Belchí, A. I., \& Romero Medina, A. (2013). Prevalencia/Comorbilidad. In C. López-Soler, \& A. R. Medina (Eds.), Trastorno por Déficit de Atención e Hiperactividad y Trastornos del Comportamiento en la infancia y la adolescencia: Clínica, Diagnóstico, Evaluación y Tratamiento (p. 25 and following). Madrid: Pirámide.

Loro López, M., Jiménez Gómez, B., \& Quintero Gutiérrez del Álamo, F. J. (2009). Trastorno por déficit de atención e hiperactividad en la adolescencia. In F. J. Quintero Gutiérrez del Álamo, J. Correas Lauffer, \& F. J. Quintero Lumbreras (Eds.), Trastorno por déficit de atención e hiperactividad (TDAH) a lo largo de la vida (3ª Edición). Barcelona: Elsevier Masson.

Lösel, F. (2013). Lecture on “What Works in Correctional Treatment and Offender Rehabilitation?”, by Professor Friedrich Lösel, MSt Programmes in Applied Criminology (Penology Programme \& Police Executive Programme), Held in the Little Hall, University of Cambridge, 4th July 2013.

Madrid Conesa, F. (2009). El impacto social del Trastorno por Déficit de Atención e Hiperactividad. Universidad de Salamanca.

Madrid Conesa, F. (2013). La situación del TDAH en España. Madrid: Adelphi Targis.

Madrid Conesa, F. (2014). TDAH y delitos. En el impacto social del TDAH. Madrid: Adelphi Targis.

Mannuzza, S., Klein, R. G., Bessler, A. M., Malloy, P., \& LaPadula, M. (1998). Adult Outcome of Hyperactive Boys: Educational Achievement, Occupational Rank, and Psychiatric Status. Archives of General Psychiatry, 50, 565-576. 
http://dx.doi.org/10.1001/archpsyc.1993.01820190067007

Martel, M. M., \& Nigg, J. T. (2006). Child ADHD and Personality/Temperament Traits of Reactive and Effortful Control, Resiliency, and Emotionality. Journal of Child Psychology and Psychiatry, 47, 1175-1183. http://dx.doi.org/10.1111/j.1469-7610.2006.01629.x

McCarthy, S., Asherson, O., Coghill, D., Hollis, C., Murray, M., Potts, L., Sayal, K., De Soysa, R., Taylor, E., Williams, T. \& Won, I. C. (2009). Attention-Deficit Hyperactivity Disorder: Treatment Discontinuation in Adolescents and Young Adults. The British Journal of Psychiatry, 194, 273-277. http://dx.doi.org/10.1192/bjp.bp.107.045245

McKee, T. E., Harvey, E., Danforth, J. S., Ulaszek, W. R., \& Friedman, J. L. (2004). The Relation between Parental Coping Styles and Parent-Child Interactions Before and after Treatment for Children with ADHD and Oppositional Behavior. Journal of Clinical Child \& Adolescent Psychology, 33, 158-168. http://dx.doi.org/10.1207/S15374424JCCP3301_15

Mick, E., Biederman, J., Faraone, S. V., Sayer, J., \& Kleinman, S. (2002). Case-Control Study of Attention-Deficit Hyperactivity Disorder and Maternal Smoking, Alcohol Use, and Drug Use during Pregnancy. Journal of the American Academy of Child and Adolescent Psychiatry, 41, 378-385. http://dx.doi.org/10.1097/00004583-200204000-00009

Milberger, S., Biederman, J., Faraone, S. V., Chen, L., \& Jones, J. (1997). ADHD Is Associated with Early Initiation of Cigarette Smoking in Children and Adolescents. Journal of the American Academy of Child and Adolescent Psychiatry, 36, 37-44. http://dx.doi.org/10.1097/00004583-199701000-00015

Minzenberg, M. J. (2012). Pharmacotheraphy for Attention-Deficit/Hyperactivy Disorder: From Cell to Circuits. Neurotherapeutics, 9, 610-621. http://dx.doi.org/10.1007/s13311-012-0128-7

Mir Puig, S. (2011). Derecho Penal. Parte General Parte General (9ª ed.). Barcelona: Reppertor.

Morillas Fernández, D. L. \& Aguilar Cárceles, M. M. (2014). El inicio de la carrera criminal en menores infractores con Trastorno por Déficit de Atención e Hiperactividad (TDAH). In F. Miró Llinares, J. R. Agustina Sanhellí, J. E. Medina Sarmiento, \& L. Summers (Eds.), Crímen, oportunidad y vida diaria. Libro Homenaje al Profesor Dr. Marcus Felson (pp. 457-492). CRÍMINA. Centro para el Estudio y Prevención de la Delincuencia. Madrid: Dykinson.

Morillas Fernández, D. L. (2013). Imputabilidad y Trastorno por Déficit de Atención e Hiperactividad. Revista Internacional de Doctrina y Jurisprudencia, 3.

Morillas Fernández, D. L., \& Luna del Castillo, J. (2006). Datos de la mujer maltratada. In L. Morillas Cueva, M. J. Jiménez Díaz, J. D. Luna del Castillo, M. T. Miranda de León, D. L. Morillas Fernández, \& I. Gracía Zafra (Eds.), Sobre el maltrato a la mujer. Un estudio de 338 casos. Madrid: Dykinson.

Morillas Fernández, D. L., Patró Hernández, R. M., \& Aguilar Cárceles, M. M. (2014). Victimología: Un estudio de la víctima y los procesos de victimización (2 ${ }^{\mathrm{a}}$ Edición). Madrid: Dykinson.

Muñoz Conde, F., \& García Arán, M. (2010). Derecho Penal. Parte General (8ª ed.). Valencia: Tirant lo Blanch.

Murphy, K., Barkley, R. A., \& Bush, T. (2002). Young Adults with Attention-Deficit Hyperactivity Disorder: Subtype Differences in Comorbidity, Educational, and clinical history. The journal of Nervous and Mental Disease, 190, 147-157. http://dx.doi.org/10.1097/00005053-200203000-00003

Namdari, P., Nzari, H., \& Pournia, Y. (2012). Epidemiologic Feature of Attention Deficit and Hyperactivity Disorder (ADHD) in Elementary School Children. Hong Kong Journal of Pediatric, 17, 162-166.

Newcorn, J. H., Halperin, J. M., \& Miller, C. J. (2010). TDAH con Negatividad y Agresividad. In Thomas E. Brown, Comorbilidades del TDAH. Manual de las complicaciones del trastorno por déficit de atención con hiperactividad en niños y adultos (2ª Edición). Madrid: Elsevier Masson. http://dx.doi.org/10.1016/b978-84-458-2021-6.00009-9

Nottelmann, E. D., \& Jensen, P. S. (1995). Comorbidity of Disorders in Children and Adolescents: Developmental Perspectives. Advances in Clinical Psychology, 17, 109-155. http://dx.doi.org/10.1007/978-1-4757-9044-3_3

Office of Justice Program (1999). Highlights of Findings from the Pittsburgh Youth Study, Office of Juvenil Justice and Delinquency Prevention, US Department of Justice. https://www.ncjrs.gov/pdffiles1/fs9995.pdf

Orts Berenguer, E., \& González Cussac, J. L. (2010). Compendio de Derecho Penal. Parte General, $2^{a}$ Edición actualizada conforma a la LO 5/2010. Valencia: Tirant lo Blanch.

Parellada Redondo, M. J. (2009) Concepto y antecedentes históricos. In M. J. Parellada Redondo (Coord.), TDAH. Trastorno por déficit de atención e hiperactividad. De la infancia a la edad adulta (p. 145). Madrid: Alianza Editorial

Pedrero Pérez, E. J. (2009). Evaluación de la impulsividad funcional y disfuncional en adictos a sustancias mediante el Inventario de Dickman. Psicothema, 21, 585-591.

Perry, J. L., \& Carroll, M. E. (2008). The Role of Impulsive Behavior in Drug Abuse. Psychopharmacology, 200, 1-26. http://dx.doi.org/10.1007/s00213-008-1173-0

Philipsen, A. (2006). Differential Diagnosis and Comorbidity of Attention-Deficit/Hyperactivity Disorder (ADHD) and Borderline Personality Disorder (BDP) in Adults. European Archives of Psychiatry and Clinical Neuroscience, 256, 142- 
146.

Philipsen, A., Limberger, M. F., Lieb, K., Feige, B., Kleindients, N., Ebner-Priemer, U., Barth, J., Schmahl, C., \& Bihus, M. (2008). Attention-Deficit Hyperactivity Disorder as a Potentially Aggravating Factor in Borderline Personality Disorder. The British Journal of Psychiatry, 192, 118-123. http://dx.doi.org/10.1192/bjp.bp.107.035782

Piquero, A., Farrington, D. P., Welsh, B., Tremblay, R., \& Jennings, W. (2008). Effects of Early Family Parent Training Programs on Antisocial Behavior and Delinquency. A Systematic Review. Stockholm, Swedish National Council for Crime Prevention: Brottsförebyggande radet. http://dx.doi.org/10.4073/csr.2008.11

Plattner, B., The, S. S., Kraemer, H. C., Williams, R. P., Bauer, S. M., Kindler, J., Feucht, M., Friedrich, M. H., \& Steiner, H. (2007). Suicidality, Psychopathology, and Gender in Incarcerated Adolescents in Austria. Journal of Clinical Psychiatry, 68, 1593-1600. http://dx.doi.org/10.4088/JCP.v68n1019

Polanczyk, G., De Lima, M. S., Horta, B. L. Biederman, J., \& Rohde, L. A. (2007). The Worldwide Prevalence of ADHD: A Systematic Review and Meta-Regression Analysis. American Journal of Psychiatry, 164, 942-948.

http://dx.doi.org/10.1176/ajp.2007.164.6.942

Popper, C. W., Gammon, G. D., West, S. A., \& Bailey, C. E. (2003). Disorders Usually First Diagnosed in Infancy, Childhood and Adolescence. In R. E. Hales and S. C. Yudofsky (Eds.), Textbook of Clinical Psychiatry (4th ed.). Washington: The American Psychiatry Publishing.

Portnoy, J., Gao, Y., Gelnn, A. L., Niv, S., Peskin, M., Rudo-Hutt, A., Schug, R. A., Yang, Y., \& Raine, A. (2013). The Biology of Childhood Crime and Antisocial Behavior. In C. L. Gibson, \& M. D. Krohn (Eds.), Handbook of Life-Course Criminology. Emerging Trends and Directions for Future Research. London: Springer. http://dx.doi.org/10.1007/978-1-4614-5113-6_2

Pueyo-Benito, R., Maññeru-Zunzarre, C., Vendrell-Gómez, P. P., Mantaroa, M., Estévez-González, E., García-Sánchez, C., \& Junqué, C. (2000). Trastorno por déficit de atención con hiperactividad. Asimetrías cerebrales observadas en resonancia magnética. Revista de Neurología, 30, 920-925.

Putnins, A. L. (2005). Correlates and Predictors of Self-Reported Suicide Attempts among Incarcerated Youths. International Journal of Therapy Comparative Criminology, 49, 143-157. http://dx.doi.org/10.1177/0306624X04269412

Quintero Olivares, G. (1999). Locos y culpables. Navarra: Aranzadi.

Quintero, F. J., Herrera, J. A., Correas, J., San Sebastián, J., García, N., \& Loro, M. (2009). Características clínicas del trastorno de déficit de atención e hiperactividad en la infancia. In Francisco Javier Quintero, Javier Correas \& Francisco Javier Quintero, Trastorno de déficit de atención e hiperactividad (TDAH) a lo largo de la vida (3 Edición, p. 136). Madrid: Elsevier Masson.

Rachel, G., Klein, R. G., \& Manuzza, S. (1991). Long-Term Outcome of Hyperactive Children: A Review. Journal of the American Academy of Child \& Adolescent Psychiatry, 30, 383-387.

http://dx.doi.org/10.1097/00004583-199105000-00005

Ramos-Quiroga, J. A., Bosch, R., \& Casas, M. (2009). Comprender el TDAH en adultos. Trastorno por déficit de atención con hiperactividad en adultos. Barcelona: Amat Editorial.

Ramos-Quiroga, J. A., Bosch-Munsó, R., Castells-Cervelló, X., Noguera-Morais, M., García-Giménez, E., \& Casas-Brugué, M. (2006). Trastorno por déficit de atención con hiperactividad en adultos: caracterización clínica y terapéutica. Revista de Neurología, 42, 600-606.

Rebellón, C. (2006). Do Adolescents Engage in Delinquency to Get the Social Attention of Peers? An Extension and Longitudinal Test of the Social Reinforcement Hypothesis. Journal of Research in Crime and Delinquency, 43, 387-411. http://dx.doi.org/10.1177/0022427806291259

Redondo Illescas, S., \& Garrido Genovés, V. (2013). Principios de Criminología (4a Edición). Valencia: Tirant lo Blanch.

Rettew, D. C., \& Hudziak, J. J. (2010). Genética del TDAH. In T. E. Brown (Ed.), Comorbilidades del TDAH. Manual de las complicaciones del trastorno por déficit de atención con hiperactividad en niños y adultos ( $2^{\mathrm{a}}$ Edición). Madrid: Elsevier Masson. http://dx.doi.org/10.1016/b978-84-458-2021-6.00002-6

San Sebastián Cabases, J., Soutullo Esperón, C., \& Figueroa Quintana, A. (2010). Trastorno por Déficit de Atención e Hiperactividad (TDAH). In C. Soutullo Esperón, \& M. J. Mardomingo Sanz (Eds.), Manual de Psiquiatría del Niño y Adolescente (p. 55 and following). Madrid: Panamericana.

Sánchez Gómez, J. (2012). Manual de Clínica Criminológica. Madrid: Tecnos.

Schachar, R., \& Tannock, R. (2002). Syndromes of Hyperactivity and Attention Deficit. In M. Rutter, \& E. Taylor, Child and Adolescent Psychiatry (4th ed., p. 405). Oxford: Blackwell Publishing.

Shaw, J., Evans, A., Eskstrand, K., Sharps, W., Blumenthal, J., Greenstein, D., Clasen, D., \& Giedd, J. (2007). Brain Matures a Few Years Late in ADHD, But Follows Normal Pattern Recent News. National Institute of Mental Health, 12. Further Information in the Following Link: 
http://www.nimh.nih.gov/news/science-news/2007/brain-matures-a-few-years-late-in-adhd-but-follows-normal-pattern.sht $\underline{\mathrm{ml}}$

Silver, L. B. (2000). Attention-Deficit/Hyperactivity Disorder in Adult Life. Child and Adolescent Psychiatric Clinical of North America, 9, 511-523.

Simon, R. I. (2003). The Law and Psychiatry. In R. E. Hales \& Stuart C. Yudofsky (Eds.), Textbook of Clinical Psychiatry (p. 1585). Washington DC: The American Society Publishing. http://dx.doi.org/10.1176/foc.1.4.349

Simon, V., Czobor, P., Balint, S., Mészaros, A., \& Bitter, I. (2009). Review Prevalence and Correlates of Adult Attention-Deficit Hyperactivity Disorder: Meta-Analysis. The British Journal of Psychiatry, 194, 204-211. http://dx.doi.org/10.1192/bjp.bp.107.048827

Slutske, W. S., Cronk, N. J., \& Nabors-Oberg, R. E. (2003). Familial and Genetic Factors. In C. A. Essau (Ed.), Conduct and Oppositional Defiant Disorders. Epidemiology, Risk Factors, and Treatment. New Jersey: Lawrence Erlbraum Associates.

Smith, C. A., \& Stern, S. B. (1997). Delinquency and Antisocial Behavior: A Review of Family Processes and Intervention Research. Social Service Review, 71, 382-420. http://dx.doi.org/10.1086/604263

Solanto, M. V. (2002). Dopamine Dysfunction in AD/HD: Integrating Clinical and Basic Neuroscience Research. Behavioral Brain Research, 130, 65-71. http://dx.doi.org/10.1016/S0166-4328(01)00431-4

Sonuga-Barke, E. J. S. (2005). Causal Models of Attention-Deficit/Hyperactivity Disorder: From Common Simple Deficits to Multiple Developmental Pathways. Biological Psychiatry, 57, 1231-1238. http://dx.doi.org/10.1016/j.biopsych.2004.09.008

Soutullo Esperón, C. (2008). Convivir con Niños y Adolescentes con Trastorno por Déficit de Atención e Hiperactividad (2 ${ }^{\mathrm{a}}$ Edición). Madrid: Editorial Médica Panamericana.

Soutullo Esperón, C., \& Díez Suárez, A. (2007). Manual de Diagnóstico y Tratamiento del TDAH. Madrid: Panamericana.

Sowell, E. R., Thompson, P. M., Welcome, S. E., Henkenius, A. L., Toga, A. W., \& Peterson, B. S. (2003). Cortical Abnormalities in Children and Adolescents with Attention-Deficit Hyperactivity Disorder. The Lancet, 22, 1699-1707. http://dx.doi.org/10.1016/S0140-6736(03)14842-8

Spencer, T., Biederman, J., Wilens, T. E., \& Faraone, S. V. (1998). Adults with Attention-Deficit/Hyperactivity Disorder: A Controversial Diagnosis. Journal of Clinical Psychiatry, 59, 59-68.

Speranza, M., Revah-Levy, A., Cortese, S., Falissard, B., Pham-Scottez, A., \& Corcos, M. (2011). ADHD in Adolescents with Borderline Personality Disorder. BMC Psychiatry, 11, 1-9.

Spivac, B., Vered, Y., Yoran-Heges, R., Averbuch, E., Metser, R., \& Graf, E. (1999). Circulatory Levels of Catecholamines, Serotonin and Lipids in Attention Deficit Hyperactivity Disorder. Acta Psychiatr Scand, 99, 300-304. http://dx.doi.org/10.1111/j.1600-0447.1999.tb07229.x

Sprich, S., Biederman, J., \& Crawford, M. H. (2000). Adoptive and Biological Families of Children and Adolescents with ADHD. Journal of the American Academy of Child and Adolescent Psychiatry, 39, 1432-1437. http://dx.doi.org/10.1097/00004583-200011000-00018

Stattin, H., \& Klackenberg-Larson, I. (1993). Early Language and Intelligence Development and Their Relationship to Future Criminal Behaviour. Journal of Abnormal Psychology, 102, 369-378.

http://dx.doi.org/10.1037/0021-843X.102.3.369

Stemmler, M., \& Lösel, F. (2012). Stability of Externalizing Behavior. Psychological Test and Assessment Modelling, 54, 195-203.

Still, G. F. (1902). The Coulstonian Lectures in Some Abnormal Psychical Conditions in Children. Lancet.

Strang-Karlsson, S., Räikkönen, K., Pesonen, A. K., Kajantie, E., Paavonen, E. J., Lahti, J., Hovi, P., Heinonen, K., Järvenpää, A. L., Eriksson, J. G., \& Andersson, S. (2008). Very Low Birth Weight and Behavioral Symptoms of Attention Deficit Hyperactivity Disorder in Young Adulthood: The Helsinki Study of Very-Low-Birth-Weight Adults. American Journal of Psychiatry, 165, 1345-1353. http://dx.doi.org/10.1176/appi.ajp.2008.08010085

Sullivan, M. A., \& Levin, F. R. (2001). Attention-Deficit/Hyperactivity Disorder and Substance Abuse. Diagnostic and Therapeutic Considerations. Annals New York Academy of Sciences, 134, 251-270.

The National Institute for Health and Care Excellence. www.nice.org.uk.

The Royal Australasian College of Psysicians (2009). Australian Guidelines on Attention Deficit Hyperactivity Disorder (ADHD). June 2009 (p. 180 y ss.). Further Information in the Following Link: http://www.nhmrc.gov.au/_files_nhmrc/publications/attachments/ch54_draft_guidelines.pdf

Thompson, L., \& Darjee, M. (2009). Associations between Psychiatric Disorder and Offending. In M. G. Gelder, N. C. Andreasen, J. J. López-Ibor, \& J. R. Geddes (Eds.), New Oxford Textbook of Psychiatry (2nd ed.). Oxford: Oxford University Press.

Tiffon Nonis, B. N., Arroyo Fernández, A., \& Sarrato Martínez, L. (2009). Una trimorbilidad forense emergente: TLP + TCI 
+ TDAH y su correlato con el abuso de sustancias tóxicas. In B. N. Tiffon Nonis (Ed.), Manual de actuación profesional en Psicopatología Clínica, Criminal y Forense: Una dimensión Jurídico-Legal. Barcelona: Bosch-Penal.

Tremblay, R. E. (2013). Development of Antisocial Behavior during Childhood. In C. L. Gibson, \& M. D. Krohn, Handbook of Life-Course Criminology. Emerging Trends and Directions for Future Research. London: Springer. http://dx.doi.org/10.1007/978-1-4614-5113-6 1

Verdejo, A., Lawrence, A. J., \& Clarck, L. (2008). Impulsivity as a Vulnerability Marker for Substance Use Disorders: Review of Findings from High-Risk Research, Problem Gamblers and Genetic Association Studies. Neuroscience \& Biobehavioral Reviews, 32, 777-810. http://dx.doi.org/10.1016/j.neubiorev.2007.11.003

Ward, M., Wender, P. H., \& Reimherr, F. W. (1993). The Wender Utah Rating Scale: An Aid in the Retrospective Diagnosis of Childhood Attention Deficit Hyperactivity Disorder. American Journal of Psychiatry, 150, 885-890.

Ward, M., Wender, P. H., \& Reimherr, F. W. (1993). The Wender Utah Rating Scale: An Aid in the Retrospective Diagnosis of Children with ADHD. American Journal of Psychiatry, 160, 245-256.

Welsh, B. C., \& Farrington, D. P. (2013). Preventing Crime Is Hard Work: Early Intervention, Developmental Criminology, and the Enduring Legacy of James Q. Wilson. Journal of Criminal Justice, 41, 448-451. http://dx.doi.org/10.1016/j.jcrimjus.2013.08.003

Wender, E. H., \& Soltano, M. V. (1991). Effects of Suger on Aggressive and Inattentive Behavior in Children with Attention Deficit Disorder with Hyperactivity and Normal Children. Pediatrics, 88, 449-456.

Westmoreland, P., Gunter, T., Loveless, P., Allen, J., Sieleni, B., \& Black, D. W. (2010). Attention Deficit Hyperactivity Disorder in Men and Women Newly Committed to Prison. Clinical Characteristics, Psychiatric Comorbidity, and Quality of Life. International Journal of Offender Therapy and Comparative Criminology, 54, 361-377. http://dx.doi.org/10.1177/0306624X09332313

Whittinger, N. S., Langley, K., Fowlerm, T. A., Thomas, H. V., \& Thapar, A. (2007). Clinical Precursors of Adolescent Conduct Disorder in Children with Attention-Deficit/Hyperactivity Disorder. Journal of the American Academy of Child \& Adolescent, 46, 179-187. http://dx.doi.org/10.1097/01.chi.0000246066.00825.53

Wilens, T. E., Biederman, J., Faraone, S. V., Martelon, M. K., Westerberg, D., \& Spencer, T. J. (2009). Presenting ADHD Symptoms, Subtypes, and Comorbid Disorders in Clinically Referred Adults with ADHD. Journal of Clinical Psychiatry, 70, 1557-1562. http://dx.doi.org/10.4088/JCP.08m04785pur

William, N. M., Zaharaieva, I., Martin, A., Langley, K., Mantripragada, K., Fossdal, R., Stefansson, H., Magnusson, P., Gudmundsson, O. O., Gustafsson, O., Homans, P., Oewn, M. J., O’Donovan, M., \& Thapar, A. (2010). Rare Chromosomal Deletions and Duplications in Attention-Deficit Hyperactivity Disorder: A Genome-Wide Analysis. The Lancet, 376, 1401-1408. http://www.cardiff.ac.uk/news/articles/adhds-genetic-link-5492.html http://dx.doi.org/10.1016/S0140-6736(10)61109-9

Williams, C. M. (2015). The Long Arm of the Law: Bringing International Drug Offenders to Justice in American Courts. Beijing Law Review, 6, 102-116. http://dx.doi.org/10.4236/blr.2015.61011

Wolraich, M. L., Hannah, J. N., Pinnock, T. Y., Baumgaertel, A., \& Brown, J. (1996). Comparison of Diagnostic Criteria for Attention-Deficit Hyperactivity Disorder in a County-Wide Sample. Journal of the American Academy of Child \& Adolescent Psychiatry, 35, 319-324. http://dx.doi.org/10.1097/00004583-199603000-00013

World Health Organization (WHO) (1992). International Classification of Diseases and Related Health Problems (ICD) (10 ${ }^{\text {th }}$ Edition). https://app.who.int

Yates, T. M., Egeland, B., \& Sroufe, L. A. (2003). Rethinking Resilience: A Developmental Process Perspective. In S. S. Luthar (Ed.), Resilience and Vulnerability. Cambridge: Cambrigde University Press. http://dx.doi.org/10.1017/CBO9780511615788.012

Yoo, H. I., Choo, S. C., Kim, B. N., Kim, S. Y., Shin, M. S., \& Hong, K. E. (2005). Psychiatric Morbidity of Second and Third Grade Primary School Children in Korea. Child Psychiatry and Human Development, 36, 215-225. http://dx.doi.org/10.1007/s10578-005-4078-8

Yoshimasu, K., Bareresi, W. J., Colligan, R. C., Voigt, R. G., Killian, J. M., Weaver, A. L., \& Katusic, S. K. (2012). Childhood ADHD is Strongly Associated with a Broad Range of Psychiatric Disorders during Adolescence: A PopulationBased Birth Cohort Study. Journal of Child Psychology and Psychiatry, 53, 1036-1043. http://dx.doi.org/10.1111/j.1469-7610.2012.02567.x

Young, S. E., Stallings, M. C., Corley, R. P., Krauter, K. S., \& Hewitt, J. K. (2000). Genetic and Environmental Influences on Behavioral Deshinibition. American Journal of Medical Genetics (Neuropsychiatric Genetics), 96, 684-695. http://dx.doi.org/10.1002/1096-8628(20001009)96:5<684::AID-AJMG16>3.0.CO;2-G

Young, S., Adamou, M., Grudjonsson, G., Müller, U., Pitts, M., Thome, J., \& Asherson, P. (2011). The Identification and Management of ADHD Offenders within the Criminal Justice System: A Consensus Statement from the UK Adult ADHD. Network and Criminal Justice Agencies. BMC Psychiatry, 11, 1-14. http://dx.doi.org/10.1186/1471-244x-11-32 
Young, S., Fitzgerarld, M., \& Postma, M. J. (2013). ADHD: Making the Invisible Visible. Expert White Paper on Attention-Deficit hyperaCtivity Disorder (ADHD): Policy Solutions to Address the Societal Impact, Costs and Long-Term Outcomes, in Support of Affected Individuals.

http://www.russellbarkley.org/factsheets/ADHD_MakingTheInvisibleVisible.pdf

Yun, I., Ball, J. D., \& Lin, H. (2011). Disentangling the Relationship between Child Maltreatment and Violent Delinquency: Using a Nationally Representative Sample. Journal of Interpersonal Violence, 26, 88-110. http://dx.doi.org/10.1177/0886260510362886

Zucker, M., Morris, M. K., Ingram, S. M., Morris, R. D., \& Bakeman, R. (2002). Concordance of Self and Informant Ratings of Adults' Current and Childhood Attention-Deficit/Hyperactivity Disorder Symptoms. Psychological Assessment, 14, 379-389. http://dx.doi.org/10.1037/1040-3590.14.4.379 